\title{
Transcriptomic analysis of poco 1, a mitochondrial pentatricopeptide repeat protein mutant in Arabidopsis thaliana
}

\author{
Hossein Emami ${ }^{1}$, Abhishek Kumar ${ }^{2,3}$ and Frank Kempken ${ }^{1 *}$ (D)
}

\begin{abstract}
Background: Flowering is a crucial stage during plant development. Plants may respond to unfavorable conditions by accelerating reproductive processes like flowering. In a recent study, we showed that PRECOCIOUS1 (POCO1) is a mitochondrial pentatricopeptide repeat (PPR) protein involved in flowering time and abscisic acid (ABA) signaling in Arabidopsis thaliana. Here, we use RNA-seq data to investigate global gene expression alteration in the poco 1 mutant.
\end{abstract}

Results: RNA-seq analysis was performed during different developmental stages for wild-type and poco 1 plants. The most profound differences in gene expression were found when wild-type and poco 1 plants of the same developmental stage were compared. Coverage analysis confirmed the T-DNA insertion in POCO1, which was concomitant with truncated transcripts. Many biological processes were found to be enriched. Several floweringrelated genes such as FLOWERING LOCUS T (FT), which may be involved in the early-flowering phenotype of pocol, were differentially regulated. Numerous ABA-associated genes, including the core components of ABA signaling such as $A B A$ receptors, protein phosphatases, protein kinases, and ABA-responsive element (ABRE) binding proteins (AREBs)/ABRE-binding factors (ABFs) as well as important genes for stomatal function, were mostly down-regulated in poco1. Drought and oxidative stress-related genes, including ABA-induced stress genes, were differentially regulated. RNA-seq analysis also uncovered differentially regulated genes encoding various classes of transcription factors and genes involved in cellular signaling. Furthermore, the expression of stress-associated nuclear genes encoding mitochondrial proteins (NGEMPs) was found to be altered in poco1. Redox-related genes were affected, suggesting that the redox state in pocol might be altered.

Conclusion: The identification of various enriched biological processes indicates that complex regulatory mechanisms underlie pocol development. Differentially regulated genes associated with flowering may contribute to the early-flowering phenotype of poco1. Our data suggest the involvement of POCO1 in the early ABA signaling process. The down-regulation of many ABA-related genes suggests an association of poco 1 mutation with the ABA signaling deficiency. This condition further affects the expression of many stress-related, especially droughtassociated genes in pocol, consistent with the drought sensitivity of pocol. pocol mutation also affects the expression of genes associated with the cellular regulation, redox, and mitochondrial perturbation.

Keywords: PPR protein, POCO1, Flowering time, Mitochondria, ABA signaling, RNA-seq, A. thaliana

\footnotetext{
*Correspondence: fkempken@bot.uni-kiel.de

'Department of Botany, Christian-Albrechts-University, Olshausenstr. 40, 24098 Kiel, Germany

Full list of author information is available at the end of the article
}

\section{$\triangle B M C$}

(c) The Author(s). 2020 Open Access This article is licensed under a Creative Commons Attribution 4.0 International License, which permits use, sharing, adaptation, distribution and reproduction in any medium or format, as long as you give appropriate credit to the original author(s) and the source, provide a link to the Creative Commons licence, and indicate if changes were made. The images or other third party material in this article are included in the article's Creative Commons licence, unless indicated otherwise in a credit line to the material. If material is not included in the article's Creative Commons licence and your intended use is not permitted by statutory regulation or exceeds the permitted use, you will need to obtain permission directly from the copyright holder. To view a copy of this licence, visit http://creativecommons.org/licenses/by/4.0/. The Creative Commons Public Domain Dedication waiver (http://creativecommons.org/publicdomain/zero/1.0/) applies to the data made available in this article, unless otherwise stated in a credit line to the data. 


\section{Background}

One of the main interests in plant biology research is to find out how plant organelles are involved in plant growth, development and adaptation to stresses. Flowering is an intricate development stage, which is controlled by various genes from different pathways. Plants integrate a number of different signals to switch to flowering [1]. Alteration in the flowering time under various stresses or adverse conditions is a strategy taken by plants to ensure reproductive life [2]. The cooperative action of various genes that contribute to flowering gives rise to the onset of this process. Comprehensive knowledge of flowering time requires the identification of all factors involved in this process.

Abscisic acid (ABA) is an endogenous phytohormone that regulates the defensive responses of plants against biotic and abiotic stresses [3] and mediates vital processes of plant growth and development [2, 4, 5]. ABA biosynthesis and signaling are rapidly activated to respond to stresses and regulate stress-related genes required for plant tolerance. Hence, $\mathrm{ABA}$ is considered to be a major stress regulator [6]. Despite the widespread ABA synthesis among algal species, ABA-dependent responses could not be found, which suggest that the ABA-mediated signaling is a key evolutionary factor in the land plants to survive desiccation [7]. Also, important roles for ABA in other developmental processes have been described such as modulation of root patterning, root cell maintenance and root xylem formation [8-10]. Pyrabactin resistance 1 (PYR1)/pyr1-like (PYL) or regulatory components of $\mathrm{ABA}$ receptor (RCAR) proteins are intracellular receptors of $\mathrm{ABA}$, either in the cytosol or the nucleus, which form a complex with the negative regulators of ABA signaling, protein phosphatase 2Cs (PP2Cs). As a result, phosphatases are inactivated and permit the interaction of sucrose nonfermenting 1related protein kinases 2 ( $\mathrm{SnRK} 2 \mathrm{~s}$ ) with nuclear targets such as ABA-responsive element (ABRE) binding proteins (AREBs)/ABRE-binding factors (ABFs) to activate ABA-responsive gene expression [6,11]. Mutants, which show alterations in ABA biosynthesis, perception, signaling, and response, show altered sensitivity to various stresses [12]. Several genes involved in stress responses function via ABA-independent and/or ABA-dependent signal-transduction cascades [4, 5]. Many ABA-inducible genes contain a conserved cis-acting ABRE, which can be recognized by AREB/ABFs [13, 14]. ABREs and $\mathrm{AREB} / \mathrm{ABF}$ are prerequisites for $\mathrm{ABA}$-dependent gene expression [15].

Apart from the primary regulation of stress responses, ABA has a key role in flowering time. Through studies on ABA-insensitive mutants, which show an earlyflowering phenotype and also exhibit inhibition of flowering by ABA treatment, the hindering effect of $\mathrm{ABA}$ on floral transition was demonstrated $[15,16]$. The inhibitory effect of $\mathrm{ABA}$ on flowering time is mediated by ABSCISIC ACID INSENSITIVE 5 (ABI5) and other ABFs (ABF1, ABF3, and ABF4), by which FLOWERING LOCUS $C$ (FLC) expression is promoted and subsequently floral integrators such as FLOWERING LOCUS $\mathrm{T}(F T)$ are repressed [17-19]. Studies found that flowering through $F T$, on the other hand, can be linked to stress-induced flowering to escape stress conditions [2].

Mitochondria are important with regards to sensing and integrating signals, stress responses and plant development [20]. Reproductive development is severely sensitive to mitochondrial mutations, which affect mitochondrial functions [21, 22]. However, molecular and genetic mechanisms behind mitochondrial activity and regulation during plant development are still mostly uncharacterized. In the case of any change in metabolic functions due to nonoptimal conditions, the communication between mitochondria and the nucleus will be altered to adapt to the new conditions. In mitochondria, reactive oxygen species (ROS) are produced as part of the normal metabolism of the mitochondrial electron transport chain (mETC). If the normal level is exceeded upon the perturbation of respiratory complexes, ROS leads to the alteration of the redox state and gene expression [23-25]. Retrograde signals regulate the expression of a large number of nuclear genes, among which are stress-responsive nuclear genes encoding mitochondrial proteins (NGEMPs) [20]. Notably, the phytohormone ABA significantly regulates mitochondrial function and can change the abundance of mitochondrial proteins [26]. It is therefore of interest to determine the molecular links between the mitochondrial function and regulation of nuclear genes, which most probably happen through retrograde signals.

In a recent study, we showed that a T-DNA insertional mutation in a mitochondrial PPR protein, POCO1, led to an early floral transition [27]. PPR proteins comprise a large family in land plants with 450 distinct members in A. thaliana and are involved in the post-transcriptional gene expression such as translation, splicing, editing, and stability of transcripts in organelles [28, 29]. poco1 prevents proper mitochondrial function demonstrated by a lower rate of respiration, a low ATP level, and a higher generation of ROS. Additionally, multiple RNA editing defects were identified in poco1. pocol plants have decreased expression levels of $A B I 5$ and FLC and enhanced expression of FT. This could explain ABA insensitivity and the early-flowering phenotype of pocol plants. These plants also showed a higher susceptibility to drought stress.

In this study, we used RNA-seq to identify target genes contributing to the function of POCO1. Several floweringassociated genes, which may explain the acceleration of floral initiation in pocol were identified. In the pocol $\mathrm{mu}$ tant, numerous genes related to ABA signaling and 
response, including $\mathrm{ABA}$-induced stress genes, were down-regulated. Likewise, genes related to drought and oxidative stresses, redox-related genes, and mitochondrial perturbation marker genes were found to be differentially regulated. Genes associated with the cellular regulation and signaling were also found to be differentially regulated.

\section{Results}

\section{Analysis of differentially expressed genes}

The RNA samples in this study were isolated at two time points: The first time point was 20 days after sowing, when wild-type plants did not yet form any inflorescence stem but poco1 plants already had (comparison 1: preinflorescence-inflorescence). The second time point was on 25 days after sowing, when wild-type plants had developed an inflorescence stem, and poco1 plants flowered (comparison 2: inflorescence-flowering). One additional comparison was performed, in which both wild-type and poco1 plants had developed an inflorescence stem (comparison 3: inflorescence-inflorescence). Thus, we analyzed wild-type and poco1 plants of the same developmental stage (Fig. 1a). Isolated RNA samples were sequenced using the Illumina platform, and after quality analysis, the reads were further trimmed. Subsequently, RNA-seq analysis was performed. RNAseq data have been deposited in the ArrayExpress database at EMBL-EBI (www.ebi.ac.uk/arrayexpress) under accession number E-MTAB-8912 (http://www.ebi.ac.uk/ arrayexpress/experiments/E-MTAB-8912/). The total number of reads for each sample has been shown in Table 1. A total number of 2645 differentially expressed genes was identified.

Gene expression alterations in poco1 were studied in different developmental stages. As presented in Fig. 1b, pre-inflorescence-inflorescence showed the fewest number of differentially regulated genes. On the other hand, inflorescence-inflorescence, representing wild-type and
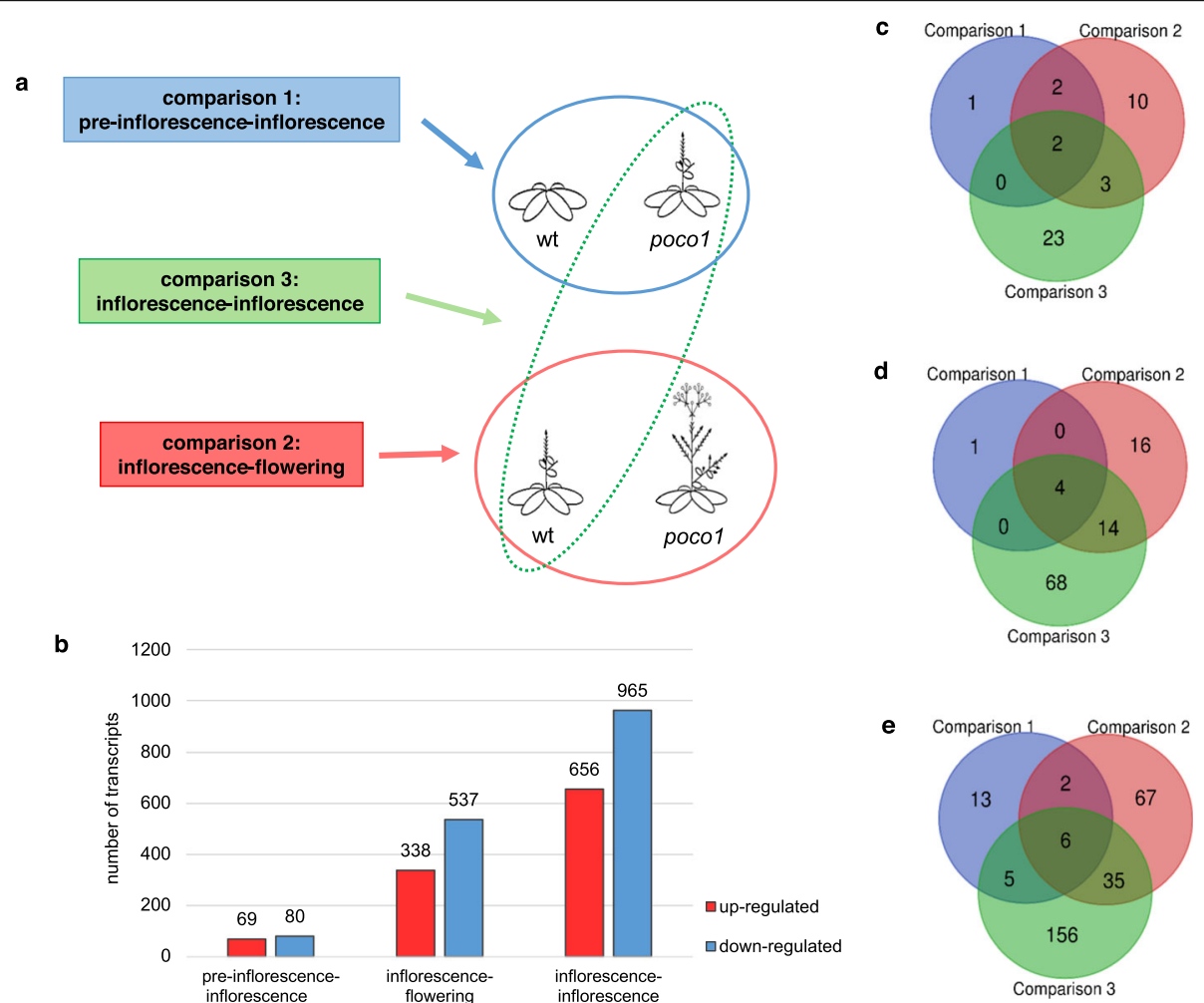

Fig. 1 Experimental setup for RNA-seq and analysis of differentially expressed genes in three comparisons. Overview of the strategy for RNA-seq and analysis of differentially expressed genes. a RNAs were isolated at two time points. Stage 1: Wild-type plants without inflorescence stem and poco 1 plants with inflorescence stem (pre-inflorescence-inflorescence). Stage 2: Wild-type plants with inflorescence stem and poco1 plants with flowers (inflorescence-flowering). Three RNA-seq comparisons were performed between wild-type and poco1. Comparisons 1 and 2 are referred to preinflorescence-inflorescence and inflorescence-flowering respectively. Comparison 3 is the comparison between wild-type and pocol plants of the same developmental stage, in which both have inflorescence stem (inflorescence-inflorescence). $\mathbf{b}$ The number of up- and down-regulated differentially expressed genes between three comparisons. Differentially expressed genes were defined as those with a fold change either $\geq 2$ or $\leq-2$ and an FDR $<0.05$. The highest number of differentially expressed genes was observed for inflorescence-inflorescence. Venn diagrams showing unique or common differentially expressed genes in each gene of interest category as $\mathbf{c}$ Flowering-related genes, $\mathbf{d}$ ABA-related genes, and $\mathbf{e}$ Drought and oxidative stress-related genes. Venn diagrams were made by an online tool (http://bioinformatics.psb.ugent.be/webtools/Venn/) 
Table 1 Number of reads of RNA-seq data. (The table belongs to the end of the first part of the result section "Analysis of the differentially expressed genes" first paragraph)

\begin{tabular}{llll}
\hline Samples & Genotypes & Developmental stage & Number of reads \\
\hline HE954_1 & wild-type & pre-inflorescence & 138.218 .582 \\
HE954_2 & wild-type & pre-inflorescence & 92.869 .772 \\
HE954_3 & wild-type & pre-inflorescence & 77.430 .678 \\
HE954_4 & poco1 & inflorescence & 81.985 .354 \\
HE954_5 & poco1 & inflorescence & 105.508 .752 \\
HE954_6 & poco1 & inflorescence & 87.081 .482 \\
HE958_1 & wild-type & inflorescence & 79.359 .440 \\
HE958_2 & wild-type & inflorescence & 88.105 .132 \\
HE958_3 & wild-type & inflorescence & 90.026 .460 \\
HE958_4 & poco1 & flowering & 111.219 .260 \\
HE958_5 & poco1 & flowering & 72.891 .436 \\
HE958_6 & poco1 & flowering & 89.512 .678 \\
\hline
\end{tabular}

poco1 plants of the same developmental stage, showed the highest number of differentially expressed genes. All differentially expressed genes (fold changes either $\geq 2$ or $\leq$ -2 , FDR $<0.05)$ allocated to the three comparisons are represented in (Additional file 1: Tables S1, S2, and S3).

To further analyze the genetic basis for poco1 phenotypes such as early flowering and ABA insensitivity, genes associated with these categories were identified and their gene expression changes studied. Due to the drought stress susceptibility and an elevated level of ROS in pocol, which is highly linked to oxidative stress, genes related to these categories in all three comparisons were identified. Venn diagrams depicted the number of common and unique up- and down-regulated genes in each category (Fig. 1c, d, and e). To obtain more evidence of other possible effects in pocol, the expression profiles of genes associated with cellular regulation were studied. Differentially expressed genes related to the redox state, stomatal function, and mitochondrial perturbation were also identified.

To understand the biological significance of gene expression in poco1, a gene ontology (GO) enrichment analysis was performed with the detected genes (fold changes either $\geq 2$ or $\leq-2$, FDR $<0.05$ ) in each comparison (Additional file 2: Figure S1). GO analysis revealed the important roles of enriched groups in the regulation of pocol in each comparison. Biological process $\mathrm{GO}$ terms related to biotic stresses and defense response such as "glycosyl compound biosynthesis," "response to biotic stimulus," "glycosinolate biosynthetic," and "sulfur compound biosynthesis process" were over-represented in the up-regulated genes of preinflorescence-inflorescence (69 genes) (Additional file 2: Figure S1). The biological process GO terms "cell redox homeostasis," "cellular homeostasis," and "electron transport chain" were enriched in the down-regulated genes of pre-inflorescence-inflorescence (80 genes) (Additional file 2: Figure S1), which may be related to the higher generation of ROS in poco1 [27]. GO enrichment of the up- and down-regulated genes of inflorescence-flowering (338 and 537 genes respectively) (Additional file 2: Figure S1) showed that various stress response-related processes are highly over-represented, which may indicate that different stresses allocate some identical pathways. Also in inflorescence-flowering, GO terms related to ageing and cell wall organization were enriched in upand down-regulated genes respectively. GO enrichment of the up-regulated genes of inflorescence-inflorescence (656 genes) (Additional file 2: Figure S1) indicated that terms associated with "translation" and "peptide biosynthetic process," as well as GO terms related to the biosynthetic and metabolic processes, were enriched. Biological process GO terms associated with nitrogen compound biosynthesis are over-represented. GO terms mainly related to stresses such as "responses to oxygencontaining compound," "response to chemicals," "response to chitin," "response to stress," "response to biotic stimulus," "defense response to other organisms," "response to organonitrogen compound," "response to water deprivation," and "response to abscisic acid" were enriched in the down-regulated genes of inflorescenceinflorescence (965 genes). The regulatory and functional attributions of drought stress responses, which are "responses to water deprivation" and "response to water," were also among the enriched biological processes (Additional file 2: Figure S1). A summary of GO enrichment analysis is represented in Fig. 2.

Based on the 25 topmost up- and down-regulated genes (Additional file 1: Tables S1, S2 and S3) three genes are commonly up-regulated in all three comparisons: PHOSPHATIDYLINOSITOL 4-KINASE GAMMALIKE PROTEIN (ATPI4K४3), Cwf18 pre-mRNA splicing factor, and PR5-LIKE RECEPTOR KINASE (PR5K). Four genes were commonly down-regulated in all three comparisons: TGG2, leucine-rich repeat [LRR] family (AT4G16880), hypothetical protein (AT5G22608), and disease resistance protein family (AT5G43740). The upregulation of $A T P I 4 K \gamma 3$ and the down-regulation of TGG2 were demonstrated to lead to an ABA-insensitive phenotype [30, 31]. Cwf18 pre-mRNA splicing factor was previously suggested to have a critical role in gene expression and abiotic stresses [32].

\section{Coverage analysis confirmed poco1 T-DNA insertional mutation with truncated transcripts}

A recent study showed that pocol carries a T-DNA insertion and was identified to be a homozygous T-DNA insertion mutant [27]. No POCO1 transcript could be identified in poco1 by RT-PCR. However, RNA-seq analysis from wild-type and poco1 showed that POCO1 


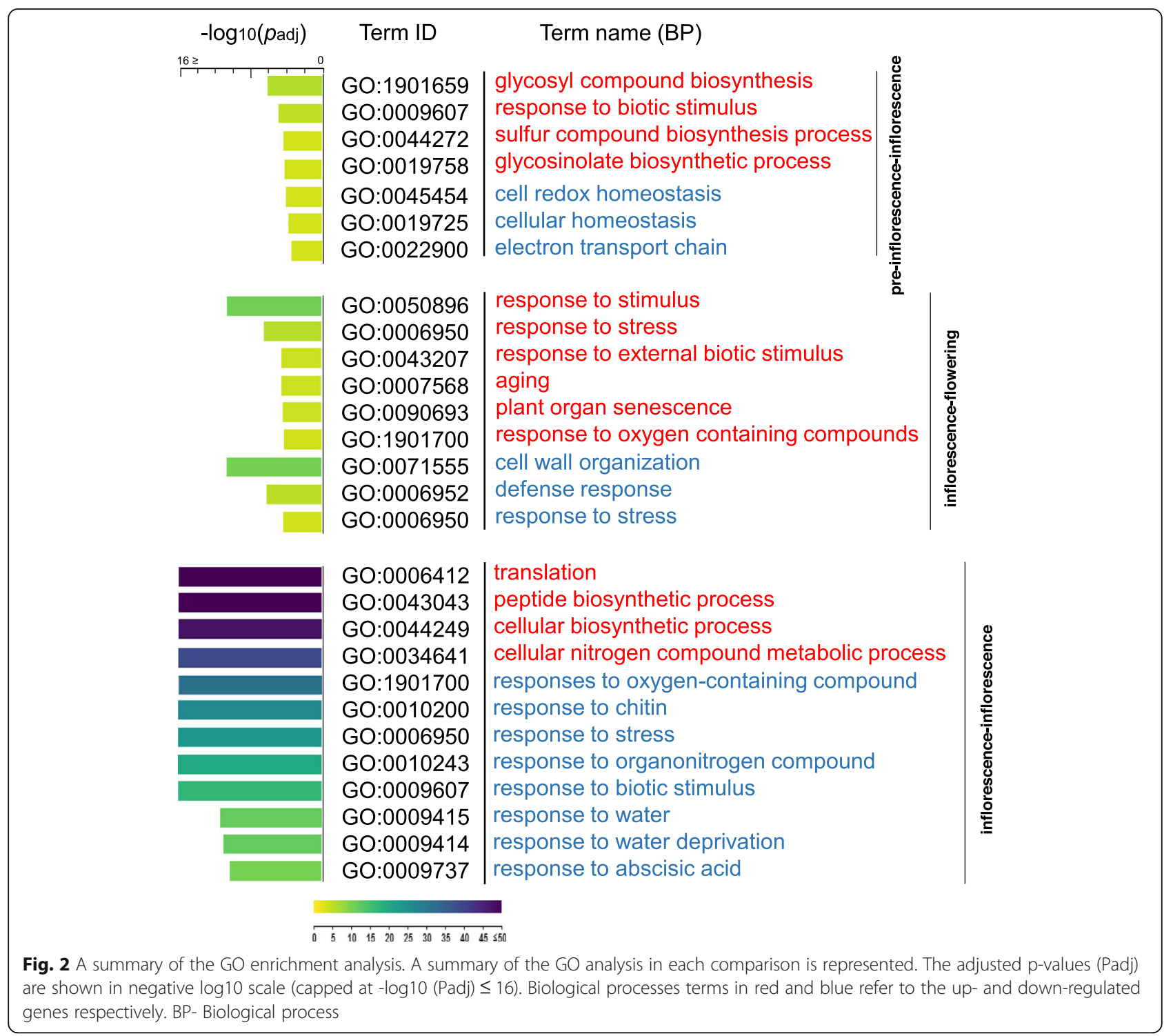

(AT1G15480) is significantly up-regulated in poco1 compared with wild-type. Therefore, we initially examined the transcript coverage in wild-type and poco1. Figure 3 shows that the abundance of the reads from +1 to + $318 \mathrm{bp}$ is extraordinarily high in poco1, which could not be observed for wild-type. Position +318 is the position of the T-DNA insertion in the POCO1 (FLAG_465F03). In the poco1 mutant, a gap exists after position +318 , which did not map to any reads. This condition indicates the presence of truncated POCO1 RNA in mutants, due to T-DNA insertion, which would not allow for translation of the POCO1 protein.

\section{Affected genes associated with flowering}

Among differentially expressed genes in three comparisons, 41 genes related to flowering, including common flowering-related genes of widely known pathways, along with other genes that contribute to flowering were identified. Gene expression analysis of flowering-associated genes may help in unravelling the mechanism of floral transition in poco1. A heat map of flowering-associated genes displays the differential regulation of these genes in different comparisons (Additional file 3: Figure S2). Identified genes belong to the photoperiod and gibberellic acid pathways. Moreover, floral integrators and a photoreceptor associated with flowering, as well as an $F L C$ specific regulator, are differentially regulated in poco1 (Additional file 3: Figure S2). RNA-seq results identified flowering-associated genes, whose up- or down-regulation fits pocol's phenotype. Based on the analysis of the differentially regulated genes associated with flowering, poco1 leads to the alteration of gene expression that results in the acceleration of flowering. Some examples of identified differentially expressed 


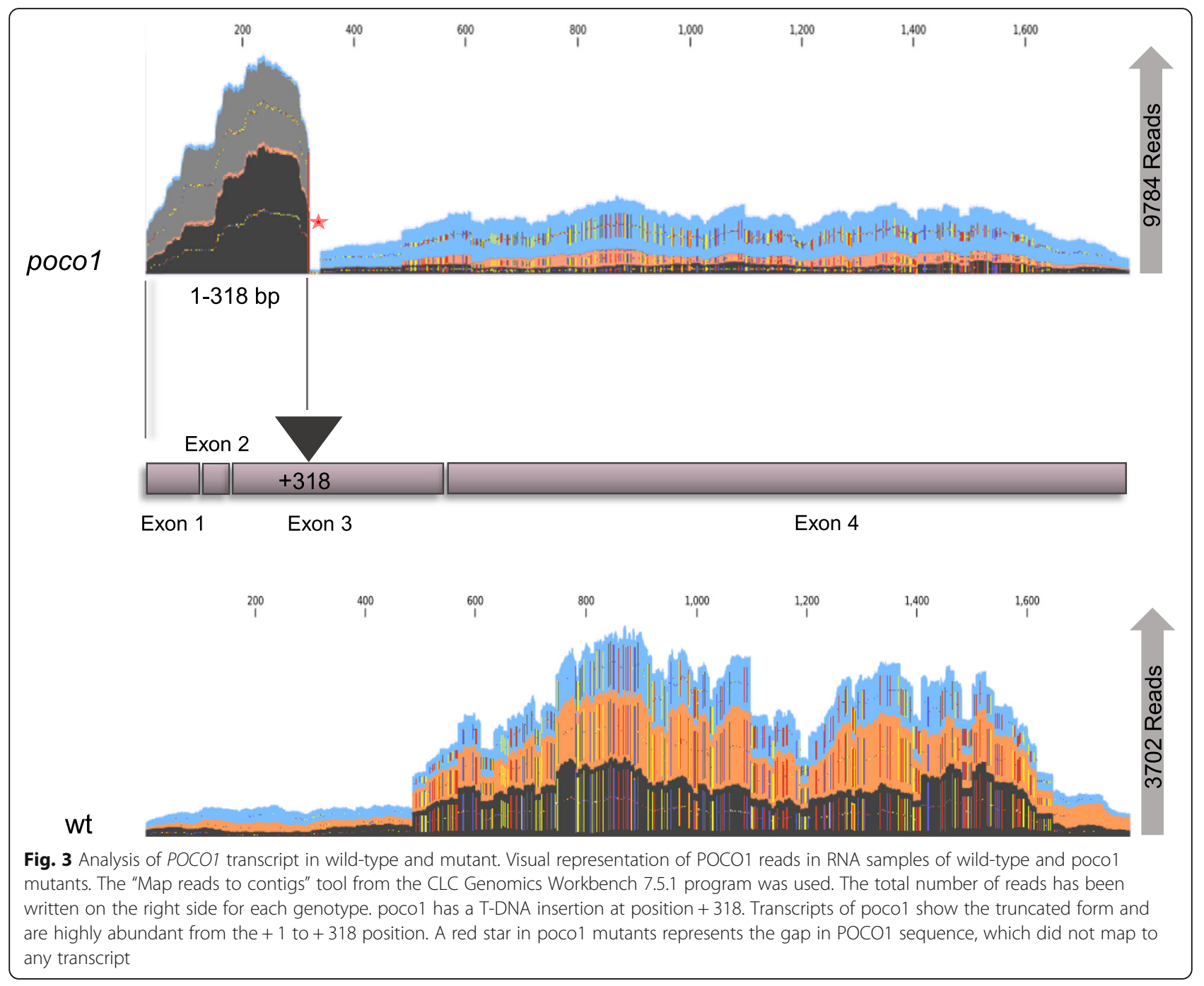

genes in pocol associated with flowering are represented in Table 2.

\section{poco1 inactivates $A B A$ signaling and response}

A recent study revealed that poco1 plants showed an insensitive phenotype to $A B A$ regarding the primary root growth and flowering time. The study showed that $A B I 5$, which acts at the core of ABA signaling, is downregulated in poco1 plants [27]. To enhance our understanding, the focus was laid on other factors associated with ABA signaling and response were searched in the differentially expressed genes in the RNA-seq results. A total of 104 genes, which are associated with ABA signaling and response in all three comparisons, were identified to be differentially expressed in poco1. A heat map of differentially expressed ABA-associated genes has been developed (Additional file 4: Figure S3). The majority of ABA-related differentially expressed genes were found in inflorescence-inflorescence and found mostly down-regulated. Interestingly, several genes functioning in the core of $\mathrm{ABA}$ perception and signaling were identified. PYRABACTIN RESISTANCE 1-LIKE 5/REGULATORY COMPONENT OF ABA RECEPTOR 8 (PYL5/ RCAR8) and PYL9/RCAR1, are involved in early ABA perception and signaling. PP2Cs such as ABA-INSENSITIVE 1 (ABI1), (ABI2), HYPERSENSITIVE GERMINATION 1 (AHG3), HOMOLOGY TO ABI 1 (HAB1), and $H A B 2$ are also down-regulated in poco1. $A B I 1$ and $A B I 2$ are type $2 \mathrm{C}$ protein phosphatases and function in $\mathrm{ABA}$ signal transduction. abi1 and abi2 have an ABAinsensitive phenotype and prevent $\mathrm{ABA}$ signal transduction [50]. Protein kinases (SnRK2), SNF1-RELATED PROTEIN KINASE 2.1 (SnRK2.1), and SnRK2.8 were found to be down-regulated in poco1. SnRK2.1 and SnRK2.8 switch on ABA signaling by phosphorylation of different target proteins [51]. ABA-activated transcription factors, ABRE-BINDING FACTOR 3 (ABF3), and $A B F 4$ are involved in ABA signal transduction. The involvement of $A B F 3$ and $A B F 4$ in water-deprivation response has been demonstrated [52, 53]. Calcium- 
Table 2 Some of differentially regulated genes in pocol and their involvement in flowering. (The table belongs to the end of the third part of the result section "Affected genes associated with flowering")

\begin{tabular}{|c|c|c|c|c|c|}
\hline Gene name & & yulation & & Description & Reference \\
\hline ACR4 & & & $\uparrow$ & up-regulated during floral induction in the apical meristem & [33] \\
\hline Ankyrin & $\uparrow$ & $\uparrow$ & & up-regulated during floral induction in the apical meristem & [33] \\
\hline CRK6 & & $\downarrow$ & $\downarrow$ & ROS sensing, signaling, mutants flower early & [34] \\
\hline CRK19 & & & $\downarrow$ & abiotic stress tolerance and hypersensitive response, mutants flower early & [34] \\
\hline DGR2 & & & $\uparrow$ & up-regulated during floral induction in the apical meristem & [33] \\
\hline ELF4-L1 & & & $\downarrow$ & circadian clock/photoperiod regulation of flowering, mutants flower early & [35] \\
\hline FLN1 & & & $\uparrow$ & up-regulated during floral induction in the apical meristem & [33] \\
\hline FLP1 & & $\uparrow$ & & floral induction, flowering time control, over-expression line flowers early & [36] \\
\hline FRL & & & $\downarrow$ & induction of $F L C$ & [37-40] \\
\hline FT & & $\uparrow$ & & positive regulation of floral induction/flower development, mutants flower late & [41] \\
\hline GA30X1 & & & $\uparrow$ & gibberellic acid biosynthetic pathway & {$[42,43]$} \\
\hline Gl & & $\uparrow$ & & induction of flowering via the circadian clock/photoperiod, mutants flower late & [44] \\
\hline GID1B & & $\uparrow$ & & gibberellic acid signaling pathway & [45] \\
\hline GRP7 & & $\uparrow$ & & regulation of flowering time, mutants flower late and over-expression line flowers early & [46] \\
\hline PHYE & & & $\downarrow$ & repressor of flowering, phototransduction, mutants flower early & {$[47,48]$} \\
\hline ROXY2 & & & $\uparrow$ & anther development & [49] \\
\hline TRM112A & & $\uparrow$ & & up-regulated during floral induction in the apical meristem & [33] \\
\hline AT1G09390 & & & $\uparrow$ & up-regulated during floral induction in the apical meristem & [33] \\
\hline AT5G56120 & & & $\uparrow$ & up-regulated during floral induction in the apical meristem & [33] \\
\hline
\end{tabular}

Gene regulation symbols from left to right refer to the regulation in pre-inflorescence-inflorescence, inflorescence-flowering and inflorescence-inflorescence respectively. Gene regulation symbols- $\uparrow$ : up-regulation; $\downarrow$ : down-regulation

dependent protein kinases (CDPKs) are $\mathrm{Ca}^{2+}$ binding sensory proteins and have been previously reported to be involved in ABA/stress signaling in Arabidopsis and other species [54, 55]. CALCIUM-DEPENDENT PROTEIN KINASE 32 (CPK32) belongs to the ABA signaling component that regulates ABA-responsive gene expression via ABF4 phosphorylation. Some examples of differentially expressed genes in poco1 that were identified to be associated with ABA signaling and response are represented in Table 3.

\section{Identification of genes associated with drought and oxidative stresses}

Our recent study showed that poco1 plants are more sensitive to drought stress and accumulate a higher amount of ROS [27]. Therefore, attention was focused on identifying differentially expressed genes associated with drought and oxidative stresses were searched from differentially expressed genes in the RNA-seq results. In this category, a relatively high number of genes were identified (Additional file 5: Figure S4). In addition to their functions in ABA signaling and response, many of ABA-induced genes act in stresses, especially drought stress. Many stress genes, which are highly induced by ABA, such as LIPID TRAN SFER PROTEIN 3 (LTPS), ERDS, RESPONSIVE TO DESICCATION (RDS), COLD-REGULATED 47 (COR47), COLD-
REGULATED 413-PLASMA MEMBRANE 2 (COR413$P M 2$ ), and $R A B 18$, are repressed in poco1 (Additional file 5: Figure S4). Moreover, genes that are regulators of ABA signaling such as PYL5/RCAR8, PYL9/RCAR1, ABI1, ABI2, SnRK2.1, SnRK2.8, ABF3, and ABF4 were reported to function in ABA-mediated responses to abiotic stresses [71, 72]. The expression level of authentic drought-induced genes such as $R A B 18$ [73] and $R D 29 A$ [74], which are marker genes of ABA signaling, is down-regulated in poco1. Overall, these results may ideally explain the higher sensitivity of poco1 to drought stress compared to wild-type plants.

In pocol a higher amount of ROS was detected than in wild-type [27]. A higher level of ROS is linked to oxidative stress conditions. Many oxidative stress-related genes in poco1 were found to be differentially regulated compared with wild-type plants (Additional file 5: Figure S4). Many of the identified genes were found to have an oxidoreductase activity, which may be associated with the higher accumulation of ROS in poco1. Some examples of the identified differentially expressed genes in poco1 associated with drought and oxidative stresses are represented in Table 4.

\section{Identification of genes associated with cellular regulation and signaling}

To provide an insight into the regulatory network that controls pocol's cellular metabolism, different classes of 
Table 3 Some of the differentially regulated genes in pocol associated with ABA. (The table belongs to the end of the fourth part of the result section "pocol inactivates ABA signaling and response")

\begin{tabular}{|c|c|c|c|c|c|}
\hline Gene name & & reg & ation & Description & Reference \\
\hline$A B F 3$ & & & $\downarrow$ & ABA signaling, $A B A$ and water deprivation response, mutants show ABA-insensitivity & [52] \\
\hline$A B F 4$ & & & $\downarrow$ & ABA signaling, $A B A$ and water deprivation response, mutants show $A B A$-insensitivity & [52] \\
\hline$A B / 1$ & & & $\downarrow$ & negative regulator of $A B A$ signaling, mutants show $A B A$ insensitivity & [56] \\
\hline$A B / 2$ & & & $\downarrow$ & negative regulator of $A B A$ signaling, mutants show $A B A$ insensitivity & [56] \\
\hline AHG3 & & & $\downarrow$ & negative regulator of $A B A$ signalling/ water deprivation & [57] \\
\hline AtPI4K४3 & $\uparrow$ & $\uparrow$ & $\uparrow$ & response to $A B A$, over-expression line shows $A B A$ insensitivity and reduced induction of $A B 15$ & [30] \\
\hline CPK32 & & & $\downarrow$ & $\begin{array}{l}\text { ABA signaling and response, over-expression line show ABA-hypersensitivity and enhanced } \\
\text { expression of ABA-regulated genes }\end{array}$ & [58] \\
\hline CYP707АЗ & & $\downarrow$ & & ABA catabolic and metabolic processes, involved in dehydration and rehydration & [59] \\
\hline HAB1 & & & $\downarrow$ & negative regulator of $A B A$ signaling & [56] \\
\hline HAB2 & & & $\downarrow$ & negative regulator of $\mathrm{ABA}$ signaling & [56] \\
\hline LTP3 & $\downarrow$ & $\downarrow$ & $\downarrow$ & ABA response & [60] \\
\hline LTP4 & $\downarrow$ & $\downarrow$ & $\downarrow$ & ABA response & [61] \\
\hline MARD1 & & & $\downarrow$ & response to $A B A$ & [62] \\
\hline MLP43 & & $\downarrow$ & $\downarrow$ & positive regulator of $A B A$ signaling, involved in drought tolerance & [63] \\
\hline NCED4 & & $\uparrow$ & $\downarrow$ & ABA biosynthesis & [64] \\
\hline PYL5/RCAR8 & $\downarrow$ & & & ABA signaling and response, drought stress response & [65] \\
\hline PYL9/RCAR1 & & & $\downarrow$ & ABA signaling and response, mutants are ABA-insensitive & {$[65,66]$} \\
\hline RAB18 & & & $\downarrow$ & ABA and abiotic stress-responsive & [63] \\
\hline RPK1 & & & $\downarrow$ & ABA signaling pathway, $A B A$ and water deprivation response, altered stress-induced responses in mutants & {$[67,68]$} \\
\hline SnRK2.1 & & & $\downarrow$ & ABA signaling, water deprivation response & [69] \\
\hline SnRK2.8 & & & $\downarrow$ & ABA signaling, water deprivation response, over-expression line enhances drought tolerance & [52] \\
\hline SYP121 & & $\downarrow$ & & response to $A B A$ & [70] \\
\hline
\end{tabular}

Gene regulation symbols from left to right refer to the regulation in pre-inflorescence-inflorescence, inflorescence-flowering and inflorescence-inflorescence respectively. Gene regulation symbols- $\uparrow$ : up-regulation; $\downarrow$ : down-regulation

Table 4 Some of the differentially regulated drought and oxidative stress genes in pocol. (The table belongs to the end of the fifth part of the result section "identification of genes associated with drought and oxidative response")

\begin{tabular}{|c|c|c|c|c|}
\hline Gene name & Gene regulation & & Description & Reference \\
\hline COR47 & & $\downarrow$ & response to water deprivation & [75] \\
\hline COR413-PM2 & & $\downarrow$ & cellular response to water deprivation & {$[76]$} \\
\hline ERD1 & & $\downarrow$ & drought stress tolerance & [77] \\
\hline ERD10 & & $\downarrow$ & response to water deprivation & [78] \\
\hline LTP3 & $\downarrow$ & $\downarrow$ & response to water deprivation & [79] \\
\hline LTP4 & $\downarrow$ & $\downarrow$ & response to water deprivation & [79] \\
\hline FRO4 & $\uparrow$ & & oxidation reduction process & [80] \\
\hline FRO7 & & $\downarrow$ & oxidation reduction process & [80] \\
\hline LTI78/RD29A & & & Response to water deprivation, response to ROS & [81] \\
\hline$P R X Q$ & $\downarrow$ & $\uparrow$ & cell redox homeostasis, cellular response to oxidative stress & [82] \\
\hline PRXR1 & & $\downarrow$ & response to oxidative stress & [83] \\
\hline RD28 & & $\uparrow$ & response to desiccation & [84] \\
\hline
\end{tabular}

Gene regulation symbols from left to right refer to the regulation in pre-inflorescence-inflorescence, inflorescence-flowering and inflorescence-inflorescence respectively. Gene regulation symbols- $\uparrow$ : up-regulation; $\downarrow$ : down-regulation 
transcription factors and genes involved in cellular signaling were identified from differentially expressed genes. Numerous transcription factors have been identified to be differentially expressed in poco1 in all three comparisons, which are classified to bHLH, bZIP, CCCH zinc finger, $\mathrm{C} 2 \mathrm{H} 2$ zinc finger, CO-like, ERF, GATA, GRAS, HMG, Homeobox, HSF, mTERF, MYB, MYB-like, NAC, NF-Y, PLATZ, RWP-RK, RAV, Sigma 70-like, TCP, and WRKY transcription factors (Additional file 6: Figure S5). Similar to other analyses, pre-inflorescence-inflorescence and inflorescence-inflorescence have the lowest and the highest number of regulated genes encoding transcription factors respectively. The majority of differentially regulated transcription factors in inflorescence-flowering were upregulated. Conversely, the majority of differentially regulated transcription factors in inflorescence-inflorescence were down-regulated. Differentially regulated genes from bHLH, MYB-like, and NAC transcription factor family showed up-regulation in inflorescence-flowering. Conversely, MYB-like and NAC transcription factors showed down-regulation in inflorescence-inflorescence. This is also the case for the majority of genes encoding Homeobox and MYB transcription factors. The highest number of regulated genes encoding transcription factors belongs to the ERF transcription factor family. Some examples of differentially expressed genes encoding transcription factors in poco1 are represented in Table 5.

Studies have reported that ABA affects the induction of many genes encoding transcription factors
[102]. As the most abundant class of transcription factors in plants, MYBs are involved in plant development, hormone signal transduction, and abiotic stress tolerance [88]. WRKY transcription factors are also one of the largest transcription factors, functioning in biotic and abiotic stresses $[98,103]$. The expression of the WRKYs in poco1 is mostly down-regulated (Additional file 6: Figure S5). WRKY2 was reported to act as a transcriptional regulator of AREBs/ABFs through binding W-box sequences (a core binding site for WRKYs) in the promoter regions of AREBs/ ABFs [98]. ABA-responsive genes such as $A B F 4$, $A B 15, M Y B 2$, and $R A B 18$ are target genes of WRKYs. Several genes involved in stress adaptation such as $R D 29 A$ and COR47 were reported to be downstream of WRKYs [98]. mTERFs are another group of transcription factors that are involved in organellar gene expression. They are mostly up-regulated in poco1. Collectively, these results suggest that the activity of a number of transcription factors that regulate critical biological processes may be altered in poco1.

Signaling molecules modulate diverse cellular responses and affect plant development, hormone and stress response pathways $[68,104]$. Analysis of RNA-seq data showed that several genes encoding proteins associated with cellular signaling such as receptor-like kinases (RLKs), receptor-like proteins (RLPs), mitogen-activated protein kinases (MAPKs), and leucine-rich repeat protein kinases (LRR-RKs) are differentially regulated in poco1 (Additional file 7: Figure S6).

Table 5 List of some of the differentially regulated genes encoding transcription factors in poco 1. (The table belongs to the end of the sixth part of the result section "identification of genes associated with cellular regulation and signaling")

\begin{tabular}{|c|c|c|c|c|c|c|}
\hline Gene name & & ulati & & TF & Description & Reference \\
\hline $\mathrm{FBH} 2$ & $\uparrow$ & $\uparrow$ & & $\mathrm{bHLH}$ & photoperiod-independent effect on flowering, over-expression line with an early-flowering phenotype & [85] \\
\hline PRE1 & & & $\uparrow$ & bHLH & over-expression line with an early-flowering phenotype, gibberellic acid-dependent response & [86] \\
\hline MYC2 & & & $\downarrow$ & $\mathrm{bHLH}$ & positive regulator of ABA signaling & [87] \\
\hline MYB2 & & $\uparrow$ & & MYB & response to $A B A$, response to water deprivation & [88] \\
\hline MYB2O & & $\uparrow$ & & MYB & positive regulator of $A B A$ signaling & [89] \\
\hline MYB32 & & & $\downarrow$ & MYB & response to $A B A$ & {$[90,91]$} \\
\hline MYB51 & & & $\downarrow$ & MYB & response to $A B A$ & [92] \\
\hline MYB73 & & & $\downarrow$ & MYB & interaction with $\mathrm{ABA}$ signaling components & [93] \\
\hline NAC089 & & & $\downarrow$ & NAC & negative regulation of flower development & [94] \\
\hline RAV1 & & & $\downarrow$ & ERF & negative regulation of flower development & [95] \\
\hline TEM1 & & & $\downarrow$ & RAV & FT repressor, mutants flower early, overexpression line flowers late & [95] \\
\hline WRKY15 & & $\downarrow$ & $\downarrow$ & WRKY & early $\mathrm{H} 2 \mathrm{O} 2$ responsive, over-expression line disrupts $\mathrm{ROS}$ and mitochondrial retrograde signaling & {$[96,97]$} \\
\hline WRKY25 & & & $\downarrow$ & WRKY & response to various abiotic stresses, $A B A$ response, over-expression line shows $A B A$ sensitivity & {$[98-100]$} \\
\hline WRKY33 & & & $\downarrow$ & WRKY & response to various abiotic stresses, $A B A$ response, over-expression line shows $A B A$ sensitivity & [98-100] \\
\hline WRKY46 & & & $\downarrow$ & WRKY & regulation of $A B A$ signaling and response to water deprivation & [101] \\
\hline
\end{tabular}

Gene regulation symbols from left to right refer to the regulation in pre-inflorescence-inflorescence, inflorescence-flowering and inflorescence-inflorescence respectively. Gene regulation symbols- $\uparrow$ : up-regulation; $\downarrow$ : down-regulation; TF- transcription factor 
Genes associated with mitochondrial perturbation show an altered expression profile

The mitochondrion plays an important role in sensing stresses and directing the cellular response [20, 105]. Mitochondrial function is disturbed by stresses, and feedback mechanisms will be activated to regulate gene expression to sustain mitochondrial and cellular functions $[105,106]$. Signals are transmitted from mitochondria to the nucleus (retrograde signal), leading to the corresponding responses by changing the nuclear gene expression. POCO1 is localized to mitochondria, and its loss of function led to mitochondrial dysfunction [27]. Therefore, the impact of retrograde signals on the expression of nuclear genes encoding mitochondrial proteins (NGEMPs) is plausible in poco1. Consistently, the RNA-seq analysis identified several NGEMPs that are targets of the mitochondrial perturbation status (Additional file 7: Figure S6). Thirty-seven genes associated with mitochondrial perturbation were identified to be differentially regulated in poco 1 in all three comparisons. A differential expression pattern of these genes hints to the existence of different pathways and signals in poco1, through which mitochondria communicate with the nucleus.

Transcripts encoding mitochondrial HSPs are particularly involved in mitochondrial dysfunctions as part of retrograde signals [107]. Two Mitochondrial HSPs, HSP60, and $m t H s c 70-1$ are found among the differentially expressed genes up-regulated in poco1. It was previously suggested that many of NGEMPs such as HSP70, AOX1a, and BCS1 may be truly ABAresponsive, as their transcript abundance was changed after ABA treatment [108]. The newly characterized gene family, domain of unknown function 295 (DUF295), was reported to be induced in Arabidopsis mutants with mitochondrial dysfunctions [109, 110]. A member of the DUF295 gene family (ATDOA11) was found up-regulated in poco1. Some examples of the identified differentially expressed NGEMPs in poco 1 are represented in Table 6.

\section{Cellular redox state may be affected in poco 1}

The redox cascade of the mitochondrial electron transport chain generates redox signals, which can further partake in gene expression and regulation. Redox-based signaling may be a crucial constituent in mitochondrianucleus communication $[105,114]$. Increased ROS directly leads to the alteration of redox status [24]. Due to the increased ROS level, alteration in the cellular redox status in poco1 is relevant. Many redox-related genes such as glutaredoxins (GRXs), glutathione s-transferases (GSTs), thioredoxins (TRXs), and rotamase cyclophilins (ROCs) were found among differentially expressed genes (Additional file 8: Figure S7). Oxidoreductases such as glutaredoxins $(G R X s)$, which have peroxidase activity, are involved in different cellular processes, especially oxidative stresses [115]. Several members of the GRX gene family that are involved in the cell redox homeostasis such as ROXY2, ROXY3, ROXY8, ROXY9, ROXY12, ROXY13, ROXY14, ROXY15, ROXY17, ROXY20, and $R O X Y 21$ are found to be differentially expressed in poco1. Several GSTs were found differentially regulated in poco1. Except one, all differentially regulated GSTs identified in inflorescence-inflorescence are downregulated. However, regulated GSTs in inflorescenceflowering show a different expression pattern than inflorescence-inflorescence, in which four of the GSTs show up-regulation and three of them show downregulation. These results support the hypothesis of cellular redox alteration in poco1, which may validate the role of POCO1 in mitochondrial function. Some examples of the identified differentially expressed genes in pocol associated with redox state are represented in Table 7.

\section{Effect of poco 1 on stomatal function}

One of the most important strategies of plants, which have evolved to adapt to adverse conditions, especially drought stress, is the control of stomatal aperture. ABAmediated stress responses involve alterations in gene expression, which finally may affect the regulation of

Table 6 Some of the differentially regulated NGEMPs in poco1. (The table belongs to the end of the seventh part of the result section "Genes associated with mitochondrial perturbation show an altered expression profile")

\begin{tabular}{|c|c|c|c|}
\hline Gene name & Gene regulation & Description & Reference \\
\hline AOX1a & $\downarrow$ & mitochondria-nucleus signaling, alternative respiration & {$[111]$} \\
\hline AOX1d & $\uparrow$ & mitochondria-nucleus signaling, alternative respiration & {$[111]$} \\
\hline ATDOA11 & $\uparrow$ & mitochondrial dysfunctions & {$[109]$} \\
\hline CRF6 & $\uparrow$ & mitochondrial retrograde response & {$[112]$} \\
\hline ERD5 & $\uparrow$ & mitochondria proline catabolic pathway, water deprivation response & [113] \\
\hline HSP60 & $\uparrow$ & $\begin{array}{l}\text { protein import into mitochondrial intermembrane space, involved in } \\
\text { mitochondrial dysfunctions as part of retrograde signals }\end{array}$ & [107] \\
\hline$m+H s c 70-1$ & $\uparrow$ & response to unfolded proteins, involved in mitochondrial dysfunctions as part of retrograde signals & [107] \\
\hline
\end{tabular}

Gene regulation symbols from left to right refer to the regulation in inflorescence-flowering and inflorescence-inflorescence respectively. Gene regulation symbols- $\uparrow$ : up-regulation; $\downarrow$ : down-regulation 
Table 7 Some of the differentially regulated genes in pocol associated with the cellular redox state. (The table belongs to the end of the eighth part of the result section "cellular redox state may be affected in poco 1")

\begin{tabular}{|c|c|c|c|c|}
\hline Gene name & Gene regulation & & Description & Reference \\
\hline GSTU4 & $\uparrow$ & $\downarrow$ & degradation of $\mathrm{H} 2 \mathrm{O} 2$, cellular redox homeostasis & [116] \\
\hline GSTF9 & $\uparrow$ & & glutathione metabolic process & {$[117]$} \\
\hline GSTF12 & $\uparrow$ & & glutathione metabolic process & [118] \\
\hline GSTU16 & & $\downarrow$ & glutathione metabolic process & [116] \\
\hline ROC2 & & $\uparrow$ & protein folding, connecting hormone signals to redox homeostasis in stresses & [119] \\
\hline ROC4 & $\downarrow$ & $\uparrow$ & protein folding, connecting hormone signals to redox homeostasis in stresses & [119] \\
\hline ROXY3 & & $\uparrow$ & cell redox homeostasis & [120] \\
\hline ROXY8 & & $\downarrow$ & cell redox homeostasis & [121] \\
\hline ROXY9 & $\uparrow$ & $\downarrow$ & cell redox homeostasis & [122] \\
\hline ROXY12 & $\downarrow$ & $\uparrow$ & cell redox homeostasis & [123] \\
\hline ROXY13 & $\downarrow$ & $\uparrow$ & cell redox homeostasis & {$[123]$} \\
\hline TRXZ & & $\uparrow$ & cell redox homeostasis & [124] \\
\hline TRX5 & & $\downarrow$ & cell redox homeostasis, oxidation-reduction process & [125] \\
\hline
\end{tabular}

Gene regulation symbols from left to right refer to the regulation in pre-inflorescence-inflorescence, inflorescence-flowering and inflorescence-inflorescence respectively. Gene regulation symbols- $\uparrow$ : up-regulation; $\downarrow$ : down-regulation

stomatal closure to regulate water loss. poco1 plants are ABA-insensitive and susceptible to drought stress. Therefore, stomatal dysfunction in poco1 is highly possible. RNA-seq results identified genes that play crucial roles in stomatal closure (Additional file 8: Figure S7). GLUCOSIDE GLUCOHYDROLASE 2 (TGG2), a highly abundant myrosinase in guard cells, is strongly down-regulated in poco1 in all three comparisons (lowest fold change in preinflorescence-inflorescence and inflorescence-flowering and the sixth lowest fold change in inflorescenceinflorescence) (Additional file 1: Table S1, S2 and S3). TGG1 revealed a differential expression pattern in inflorescence-flowering and inflorescence-inflorescence. Cyclic nucleotide-gated channels (CNGCs), a family of plant ion channels, are expressed in response to abiotic stresses leading to the tolerance mechanism [126].
Another hint for potential stomatal failure comes from the down-regulation of RESPIRATORY BURST OXIDASE HOMOLOGUE D (RBOHD) in poco1 [127]. The function of RBOHD was reported to be impaired in gca2 ABAinsensitive mutant [128]. GRP7 is expressed extensively in guard cells and influences stomatal opening and closure, thereby causes lowered dehydration tolerance [129, 130]. These results propose that poco1 mutation may lead to stomatal failure. Some examples of the identified differentially expressed genes in pocol associated with stomatal function are represented in Table 8.

\section{Discussion}

Transition to flowering is a critical step in the plant life cycle as it ensures the plant species continuity. Various factors involved in flowering have been identified.

Table 8 Some of the differentially regulated genes in pocol associated with stomatal function. (The table belongs to the end of the ninth part of the result section "effect of pocol on stomatal function")

\begin{tabular}{|c|c|c|c|c|}
\hline Gene name & Gene regulation & & Description & Reference \\
\hline$A B / 1$ & & $\downarrow$ & regulation of stomatal movement, mutants failed to activate anion channels in guard cells & {$[131,132]$} \\
\hline$A B I 2$ & & $\downarrow$ & regulation of stomatal movement, mutants failed to activate anion channels in guard cells & {$[131,132]$} \\
\hline CNGC1 & & $\downarrow$ & highly expressed in guard cells, ion channel & [133] \\
\hline CNGC6 & & $\downarrow$ & highly expressed in guard cells, ion channel & [133] \\
\hline GRP7 & $\uparrow$ & & enhancement of stomatal opening & [130] \\
\hline MYB44 & & $\downarrow$ & over-expression line shows enhanced stomatal closure & [91] \\
\hline $\mathrm{RBOHD}$ & & $\downarrow$ & increasing cytosolic $\mathrm{ca}^{2+}$, induced by ABA & [127] \\
\hline RPK1 & & $\downarrow$ & mutants show insensitivity in ABA-induced stomatal closure & [134] \\
\hline TGG1 & $\downarrow$ & $\uparrow$ & regulation of stomatal movement, ABA-mediated stomatal closure & {$[135,136]$} \\
\hline TGG2 & $\downarrow$ & $\downarrow$ & regulation of stomatal movement, ABA-mediated stomatal closure & {$[135,136]$} \\
\hline
\end{tabular}

Gene regulation symbols from left to right refer to the regulation in pre-inflorescence-inflorescence, inflorescence-flowering and inflorescence-inflorescence respectively. Gene regulation symbols- $\uparrow$ : up-regulation; $\downarrow$ : down-regulation 
However, the characterization of POCO1, a mitochondrial PPR protein, whose corresponding mutant exhibited an early-flowering phenotype, would provide additional information regarding mitochondria-nucleus interactions. In this study, RNA-seq data were used to better understand POCO1's function and to determine other factors that could lead to pocol's phenotype. Interestingly, the majority of differentially expressed genes were identified through inflorescence-inflorescence, in which the plants are in the same developmental stage, which may suggest a high variation in metabolic processes in each same developmental stage between wildtype and poco1 plants. Also, it may be due to the developmental reprogramming before sexual reproduction, which may have occurred more intensively in poco1. Besides, although being in the same developmental stage, they are not the same age. The coverage analysis of POCO1 confirmed the truncated transcripts in poco1 plants, which would not allow for the translation of functional POCO1.

The GO enrichment for the up- and down-regulated genes of each comparison suggests the crucial roles of those biological processes, in particular, the overrepresentation of many processes associated with response to stresses in regulating the developmental processes in poco1. Enriched biological processes related to the defense response may be due to the interaction of plant defense pathways and transition to the reproductive phase. A significant link between the regulation of glucosinolate content and flowering time in Aethionema arabicum (Brassicaceae) has been identified. FLC was determined to be the potential regulator of glucosinolate content [137]. Moreover, the glucosinolate and glycosinolate biosynthetic processes (enriched for the upregulated genes in pre-inflorescence-inflorescence) are considered as principal regulators in the transition phase and facilitate the protection of plants against pathogens during flowering [138]. These compounds are composed of sulfur and nitrogen. Interestingly, TGG2, which is highly down-regulated in poco1 in all comparisons, was demonstrated to be required for glucosinolate breakdown [135]. GO terms associated with ageing may emphasize the forefront developmental maturation of poco1, and as a logical consequence of ageing-related processes, cell wall organization and biogenesis were shown to be enriched for the down-regulated genes of inflorescence-flowering. The GO terms "translation" and "peptide biosynthetic process," along with terms associated with "ribosome assembly," which are highly enriched for the up-regulated genes of inflorescenceinflorescence, may indicate control of ribosomes. Hence, de novo protein synthesis is essential for the floral transition in poco1. Alteration in the translational machinery has been reported in A. thaliana under stress conditions
[139]. This condition may highlight the importance of the translation apparatus in pocol, which bears with unfavorable conditions. Accordingly, Cwf18 pre-mRNA splicing factor (among the top 10 most up-regulated genes in all three comparisons) was reported to function in the early response to abiotic stresses. Cwf18 premRNA splicing factor was suggested to function in the gene expression process and act along with proteins that function as part of the ribosome [32]. Therefore, its overexpression may further support the reprogramming of stress-induced transcriptional events in poco1. Studies have reported that plants can utilize the required nitrogen from organic compounds such as proteins and amides $[140,141]$. In line with the GO biological process terms related to nitrogen compound biosynthesis processes, protein and amide biosynthesis processes are highly enriched for the up-regulated genes of inflorescence-inflorescence. Availability of nitrogen is a limiting factor for plant growth and development, which controls developmental phase change [142, 143]. Some studies showed that a higher nitrogen condition promoted flowering in Arabidopsis [144-147]. The GO terms "response to abscisic acid" and "response to water deprivation," which are observed for the down-regulated genes of inflorescence-inflorescence, may explain the impaired ABA signaling and susceptibility of poco1 to drought stress.

We found several genes functioning in promoting flowering and therefore are crucial to the early floral transition in poco1. Consistent with our recent study [27], the floral integrator $F T$ is strongly up-regulated in poco1 in inflorescence-flowering. Interestingly, one of its integrators, GI, was also found to be up-regulated in poco1 in inflorescence-flowering. Expression of GI was previously reported to be a stress escape response, and the early floral transition in Arabidopsis in response to stress requires GI [148]. Except for GI, FT is also involved in stress-induced flowering [148, 149], which is an indication of the important role of these genes under unfavorable conditions to shorten the life cycle by promoting floral transition. Beyond that, these data strengthen the idea that the early flowering in pocol may be related to stress-induced flowering. This result is consistent with GO enrichment analysis of all differentially expressed genes, in which many terms were found related to response to stresses. From the RNA-seq results, we also identified that a repressor of FT, TEMPRANILLO 1 (TEM1), and a promoter of FLC, FRIGIDALIKE (FRL), both showed down-regulation in pocol. Besides, loss of function of GRP7 was reported to increase the total functional sense $F L C$ transcript and delays flowering time [150]. This result further highlights the hypothesis that the early flowering of pocol occurs via repression and elevation of $F L C$ and $F T$ respectively (Fig. 4). Except for the direct repression of FT, TEM1 


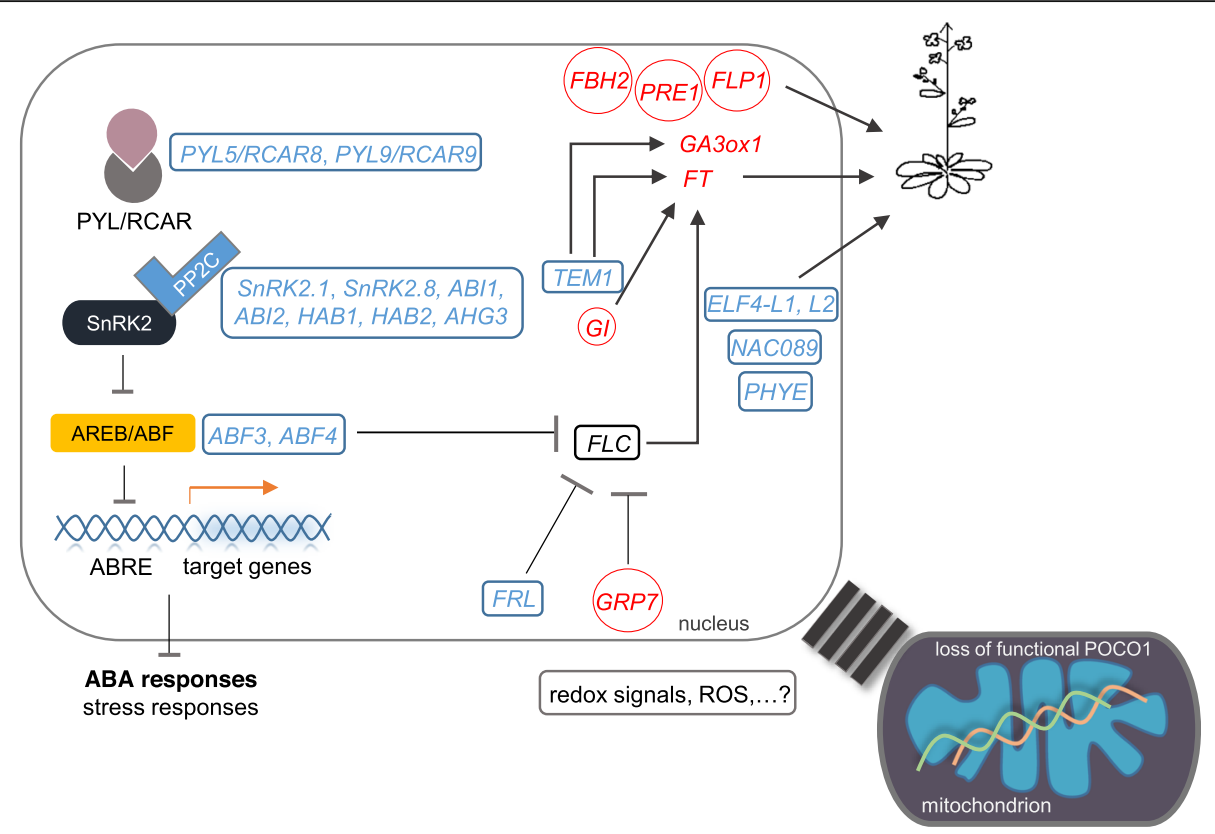

Fig. 4 Affected genes in core components of ABA signaling and flowering in pocol in a schematic representation. In Arabidopsis, multiple factors affect flowering time to adapt the unfavorable conditions. In poco1 mutants, the core ABA signaling genes (PYRs/PYLs/RCARs, PP2Cs, SnRK2s and AREBs/ABFs) are down-regulated, which may lead to an impaired ABA and stress response. Down-regulation of ABF3 and ABF4, FRL and upregulation of GRP7 may have an inhibitory effect on FLC expression. Besides, down-regulation of TEM1 and up-regulation of GI may induce FT expression. Down-regulation of TEM1 also induces the gibberellic acid biosynthesis gene, GA3ox1. Down-regulation of ELF4-L1, ELF4-L2, NAC089 and PHYE and up-regulation of FLP1, PRE1 and FBH2 are consistent with the early-flowering phenotype. Red and blue genes indicate up- and down-regulated genes respectively. Arrows and dashed arrows are indicative of inducing and inhibiting effects respectively

also suppresses the expression of GA3ox1 by directly binding to the GA3ox1 loci [151]. A gibberellic acid biosynthesis gene GA3ox1 was demonstrated to have a predominant role in plant development [42, 43]. Two functionally redundant gibberellin receptors, GIBBERELLIN-INSENSITIVE DWARF 1 (GID1B) and GID1C [45] from the gibberellic acid signaling pathway, were differentially regulated in poco1. PACLOBUTRAZOL RESIST$A N C E 1$ (PRE1) over-expression line leads to the gibberellin-dependent response and activates a branch pathway of gibberellin signaling [86]. FLOWERING PROMOTING FACTOR 1 (FLP1), was demonstrated to promote flowering time in the gibberellic acid-dependent signaling pathway in Arabidopsis [152]. These results may suggest a role for gibberellic acid in the floral transition of poco1. Besides, the up-regulation of $F B H 2$, $P R E 1$, and FLP1 and the down-regulation of PHYTOCHROME E (PHYE), EARLY FLOWERING-LIKE1 (ELF4-L1), RELATED TO ABI3/VP1 1 (RAV1), NAC089, CYSTEINE-RICH RECEPTOR-LIKE KINASE 6 (CRK6), and CRK19 allow an early-flowering phenotype (Fig. 4).

Loss of function of POCO1 leads to the ABAinsensitivity phenotype [27]. We provided evidence that numerous genes associated with ABA signaling and response are down-regulated in poco1. ATPI4K $\gamma 3$ is the most upregulated gene in pocol in pre-inflorescence-inflorescence and is also among the highest up-regulated genes in other two comparisons (Additional file 1: Table S1, S2 and S3). The function of ATPI4Ky3 is important during development and under abiotic stress conditions. Over-expression of $A T P I 4 K \gamma 3$ leads to the increased tolerance to ABA with reduced induction of $A B I 5$, which is consistent with poco1. RECEPTOR-LIKE PROTEIN KINASE 1 (RPK1) is involved in early ABA perception in Arabidopsis and acts as a regulator of ABA signaling in early steps. Therefore, it affects many downstream genes in ABA signal transduction [67, 68]. The RNA-seq analysis identified genes from the different components of ABA signaling: ABA receptors (PYL5/ RCAR8 and PYL9/RCAR1), protein phosphatases (ABI1, $A B I 2, A H G 3, H A B 1$, and $H A B 2)$, protein kinases (SnRK2.1 and SnRK2.8), and AREB/ABFs (ABF3 and ABF4). Therefore, ABA signaling pathways are disrupted from the early perception to the expression of many ABA-responsive genes in poco1 (Fig. 4). Functional ABA signaling is essential for stress tolerance, particularly drought stress $[4,5,11]$. Many genes associated with drought stress contain cis-acting ABRE and dehydration-responsive element (DRE) [153]. Studies have demonstrated that ABFs bind to ABRE elements to activate ABA-responsive gene expression, which is crucial to drought stress tolerance $[16,72]$. Therefore, the down-regulation of $A B F s$ in poco1 such as $A B F 3$ and $A B F 4$ is likely to be one possible scenario for the 
down-regulation of many ABA-induced stress-responsive genes, as shown in this study. Another intriguing feature of $\mathrm{ABFs}$ is their impact on floral transition. It has been reported that except ABI5, other ABFs can distinctly promote the expression of $F L C$ via binding to ABRE elements in the promoter region of $F L C$ [18]. Thus, it is probable that except ABI5, ABF3 and ABF4 have a direct effect on the repression of FLC in poco1 (Fig. 4). Of particular note, the inhibitory role of ABFs on FLC expression is possibly adjusted through SnRK2s, which function to phosphorylate ABFs. This modulation directly affects floral transition [18]. However, FLC and $A B I 5$ were not identified as differentially expressed genes in the RNA-seq analysis. The up-regulated expression of NCED4 in inflorescence-flowering and the down-regulated expression of CYP707A3 in the same comparison may suggest an imbalance in ABA biosynthesis and catabolism in poco1. This imbalance can also be observed in inflorescence-inflorescence, where NCED4 is downregulated, but no genes with $\mathrm{ABA}$ catabolism function were detected.

Many well-known positive effectors or regulators of drought stress such as RDs, ERDs, RAB18, and COR47 were found down-regulated in poco1. Consequently, as shown in our recent study, pocol plants were more susceptible to drought stress, and thus, poco1 negatively regulates drought response. Although ABA initially demonstrated to orchestrate abiotic responses, further studies reported the additional involvement of $\mathrm{ABA}$ in abiotic stresses. ABA confers resistance to pathogens and diseases $[154,155]$. Enriched biological processes associated with abiotic stresses thus may allegedly be due to the ABA signaling impairment in pocol, which may lead to the alteration in the expression of biotic stress-associated genes. Our RNA-seq analysis also identified many genes associated with the oxidation-reduction process, which may refer to the elevated intracellular levels of ROS, as observed previously in poco1 plants [27].

An important role of ABA in drought stress is to modulate stomatal closure, preventing less transpirational water loss [156]. ABA promotes stomatal closure by regulating the many genes involved in dehydration tolerance [157]. Our transcriptomic data support the hypothesis that the stomatal closure in poco1 may fail. TGG1 and TGG2 are two myrosinases and demonstrated to be an important components of the ABA signaling in guard cells [136]. It was reported that TGG1 and TGG2 have functional redundancy in ABA signaling in Arabidopsis guard cells [31]. Studies have demonstrated that SnRK2s have critical functions in stomatal movements [158]. Therefore, it can be speculated that the lower induction of $S n R K 2.1$ and SnRK2.8 might have negative effects on stomatal regulation in poco1. Furthermore, alteration in the expression of GRP7, RPK1, CNGCs, RBOHD, CPK6, ABI1, ABI2, and $M Y B 44$ in pocol, which are involved in stomatal regulation, may result in the stomatal closure not operating properly. This condition would consequently enhance the water loss in poco1, which does not allow drought tolerance. Furthermore, these results hint to the importance of ABA and ROS in control of stomatal function [159].

The expression of many transcription factors from different classes is altered in different developmental stages in poco1, suggesting that developmental processes in poco1 are controlled by a complex transcriptional regulation. The ERF transcription factor family, which is implicated in the transcriptional regulation of diverse cellular functions related to growth and development, responds to environmental stimuli [160]. The bHLH transcription factors bHLH81 (FBH2) and bHLH136 (PRE1), NAC transcription factor (NAC089), RAV (TEM1), and ERF (RAV1) transcription factors were demonstrated to affect flowering. The WRKY and MYB transcription factors are reported to be involved in ABA signaling [88, 100]. The differentially regulated genes encoding transcription factors that are involved in ABA signaling are as follows: WRKY2, WRKY33, WRKY25, WRKY46, MYB20, MYB32, $M Y B 51, M Y B 73$, and MYB44. Other groups of differentially regulated transcription factors in poco1 such as bZIP, $\mathrm{CCCH}$ zinc finger, $\mathrm{C} 2 \mathrm{H} 2$ zinc finger, ERF, GATA, GRAS, Homeobox, and MYB-like are involved in several plant processes. The common biological processes associated with these regulatory proteins are involvement in stress and development regulation. The most probable explanation is the deficient ABA signaling in pocol, which affects stress tolerance and plant development. Besides, studies reported the significant involvement of $\mathrm{NAC}, \mathrm{CCCH}$ zinc finger, bHLH, and WRKY transcription factors in modulating the stress response and flowering [85, 94, 161-163]. Based on the previous report [23], several transcription factors bind to transcripts from all five respiratory complexes in mitochondria and function as regulators of mitochondrial gene expression. Several genes encoding these transcription factors were found to be differentially expressed in poco1 in our RNA-seq results, including WRKY15, WRKY30, WRKY33, ABF4, Athb-6, bZIP10, bZIP25, and bHLH81.

MAPK cascades are involved in the ABA signaling and stress tolerance and are triggered by a wide range of signals including ABA, auxin, ethylene, ROS, and pathogens [164]. Thus, the down-regulation of MAPK cascades may be affected by the ABA deficiency in pocol (Fig. 5). MAPKs frequently regulate a wide range of downstream events and thus define downstream signals. Therefore, any change in their expression may lead to changes in other signaling factors $[165,166]$. RLPs are membrane-bound signaling molecules, which contain an extracellular receptor domain and can be transferred into the nucleus, chloroplast, or mitochondria. RLPs act to improve plant responses to biotic and abiotic stresses [167]. Alteration in 


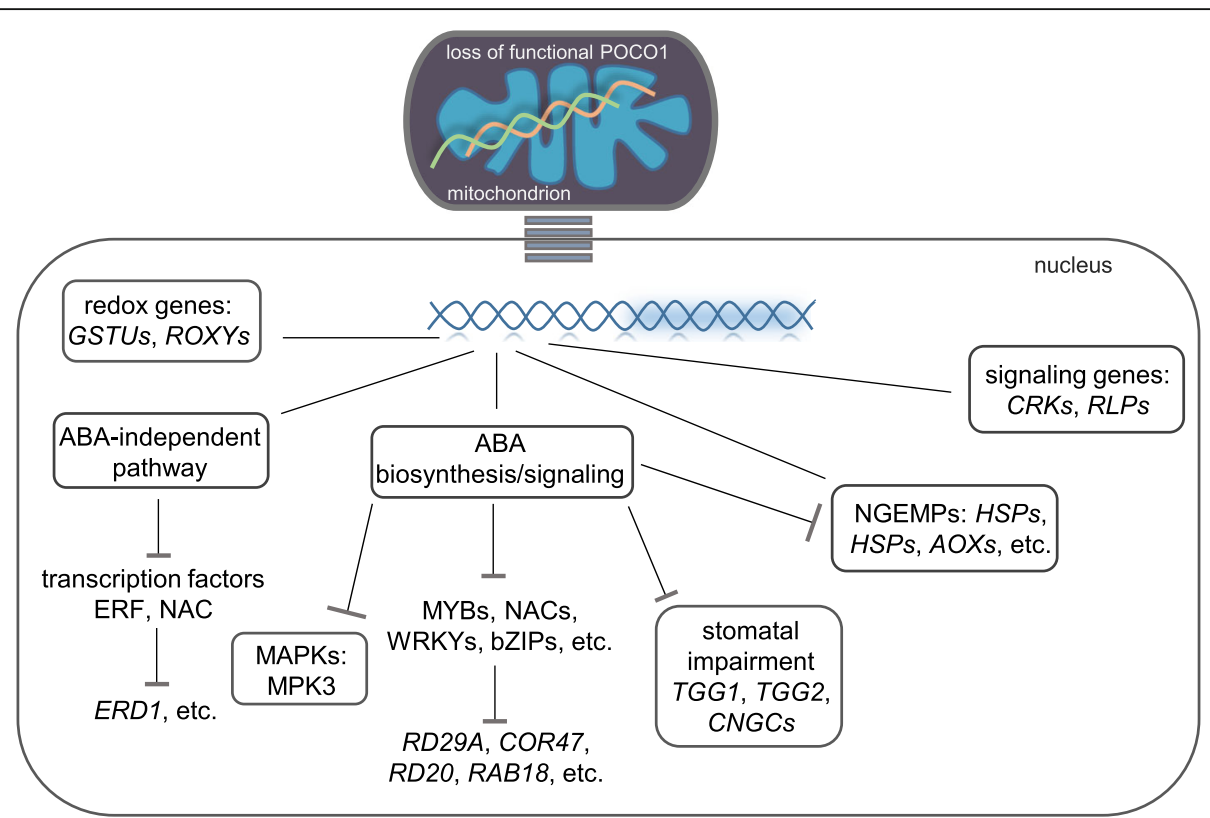

Fig. 5 The possible regulatory network of the gene expression in response to the loss of function of POCO1 in mitochondria. Loss of function of POCO1 is sensed by mitochondria. Subsequently, a retrograde signaling cascade may be activated to launch the gene expression changes. Several transcription factors, which control stress-inducible gene expression are affected. Several processes may be under the influence of defected ABA signaling in poco1. Black lines indicate crosstalk and differential regulation. Dashed arrows are indicative of possible inhibiting effects

the induction of genes such as $R L K s$, CRKs, MAPK cascades, $L R R-R K S$, and RLPS may emphasize the impact of pocol on cellular signaling.

Redox signals are involved in various aspects of plant biology and are specifically critical in cross-tolerance phenomena, allowing a general acclimation of plants to stressful conditions [24]. As genes related to the redox cascade such as GRXs, GSTs, TRXs, and ROCs were found to be differentially regulated, the redox state in pocol may be altered. This hypothesis is supported by the higher accumulation of ROS in poco1 plants and the further fact that change in the ROS level leads to the redox state alteration [24]. Redox-based signaling is an attractive candidate to be a key constituent in the mitochondria-nucleus communication cascade $[105,114,168,169]$. However, it has been proven that retrograde signaling exploits factors expanded in other contexts such as signaling factors associated with MAP kinase or ABA signaling [103]. Therefore, a general mitochondrial stress response appears linked to ABA signaling [170]. Glutathione s-transferases (GSTs) are a family of enzymes that catalyzes the conjugation of reduced GSH to a wide range of substrates and modulates GSH homeostasis to regulate development in Arabidopsis [171]. Previous studies demonstrated that GST transcripts are induced in plant tissues in response to the exogenous application of GSH, ABA, and ethylene [172, 173]. Thus, the lower induction of several GSTs in poco1 may be supposedly due to ABA signaling and response defect. Stresstolerant phenotypes, particularly drought stress, can be sufficiently explained by the greater glutathione (GSHs), $\mathrm{ABA}$ accumulation, and fine-tuned ABA signaling [174, 175]. Moreover, a lower GSH redox state was shown to lead to the early flowering in Oncidium orchid [176]. These pieces of evidence are consistent with early flowering and sensitivity to the drought stress phenotype of pocol.

In case of any change in the cellular or metabolic status in organelles (e.g., ROS accumulation), the transcript level is adjusted to optimize organellar proteome. Due to the involvement of NGEMPs to a wide range of mitochondrial perturbations, they represent different expression characteristics, and this condition points toward the possibility of the existence of multiple mitochondrial retrograde regulations [23]. As ABA affects the induction of ALTERNATIVE OXI$D A S E$ 1a (AOX1a) [177], and due to the presence of the potential binding sites of ABA-responsive elements in the promoter region of $A O X 1 a$ [23, 177], repression of $A O X 1 a$ might be under the influence of corrupted ABA signaling in pocol (Fig. 5). However, aoxla plants were shown to accumulate higher superoxide radicals and were more sensitive to drought and light stresses, which is consistent with the poco1 phenotype $[178,179]$. Enhanced induction of stress-responsive AOX1d suggests the activation of the compensatory AOX pathway in pocol mutant mitochondria. The alteration of expression of many genes in pocol, in particular, NGEMPs on one hand and the redox state genes, on the other hand, offers the possibility for the presence of retrograde signals from mitochondria to the nucleus. 


\section{Conclusion}

We used RNA-seq analysis to provide an overview of the global transcriptome changes in poco1 during different developmental stages. Most of the differentially regulated genes were identified in inflorescence-inflorescence, and the result asserts the necessity of biological analysis in different developmental stages. Different biological processes were enriched in different comparisons, which indicates that various processes are involved in the regulation of poco1. Differentially expressed genes in diverse developmental stages associated with flowering, ABA signaling and response, drought and oxidative stresses, redox state, and genes associated with mitochondrial perturbation were identified. Based on the RNA-seq results, poco1 leads to the differential regulation of some flowering genes, which affect flowering time promotion. Moreover, pocol considerably affects ABA signaling from its early signal transduction. Our data support the alteration of redox state in poco1. Furthermore, alteration in the redox state and NGEMPs expression highlights the presence of retrograde signals to transmit their functional status to regulate plant development. According to these data and our previous study, the impairment of mitochondrial function in pocol and a higher generation of ROS may cause redox imbalance, which affects the expression of many genes including ABA-, flowering-, and stress-associated genes and further causes lower tolerance to drought stress. Overall, the data generated in this study can be used to facilitate further investigations of the molecular mechanisms underlying flowering time and ABA signaling associated with mitochondrial proteins and improve the knowledge about the PPR protein family.

\section{Methods}

\section{Plant materials}

In this study, Arabidopsis thaliana plants wild-type, WS-4 (Wassilewskija), and poco1 mutants (FLAG_465F03) [180] were used. Wild-type and FLAG_465F03 were obtained from the Versailles Arabidopsis Stock Center (INRA; http://publiclines.versailles.inra.fr/). Plants were grown under controlled conditions in the growth chamber at $22{ }^{\circ} \mathrm{C}$ with $65 \%$ relative humidity, a light intensity of $110 \mu \mathrm{mol} \mathrm{m}^{-2} \mathrm{~s}^{-1}$, and the photoperiod of $16 \mathrm{~h}$ light and $8 \mathrm{~h}$ dark. Samples for RNA isolation and RNA-seq analysis were harvested two and a half hours after the start of the day period (11:00 AM).

\section{RNA isolation and RNA-seq}

Total RNA was isolated from wild-type and pocol plant leaves using TRIzol (Peqlab, Erlangen, Germany). RNA degradation and contamination were examined on a $2 \%$ agarose gel. Three biological replicates were performed for each stage for each genotype, for a total of 12 samples. RNA sequencing was performed by GATC Biotech AG (Konstanz, Germany) using Illumina technology by the HiSeq 2000 machine (125 bp paired-end reads). All steps performed have been developed and validated by GATC Biotech AG.

\section{Differential gene expression analysis}

Obtained raw sequences were evaluated by the CLC Genomics Workbench 7.5.1 program from CLC Bio (Qiagen, Hilden) based on the principles of [181]. The RNA-seq data initially went through quality control and were trimmed. The trimmed sequences were mapped to the unmasked version of Arabidopsis thaliana (WS-0) reference genome from the 1001 Genomes Project (https://1 001genomes.org/) (http://mtweb.cs.ucl.ac.uk/mus/www/1 9genomes/fasta/). The annotated gene model was used according to Arabidopsis genome annotation (TAIR10). Expression levels derived from the RNA-seq data Reads per Kilobase per Million mapped reads (RPKMs) [181] and fold changes were reported using CLC Genomics Workbench 7.5.1. CLC Genomic workbench 7.5.1 follows RNAseq protocol proposed by [181]. The false discovery rate $($ FDR $)<0.05$ was chosen as the cut-off threshold for the identification of significant expression differences [182]. Differentially expressed genes were defined as those with a fold change either $\geq 2$ or $\leq-2$.

\section{Gene ontology, Venn diagrams, and heat maps}

The unique gene identifiers were obtained for each category and were then used for gene ontology (GO) enrichment analysis. The GO enrichment was performed with the set of background genes (those detected in each comparison) using the g:profiler online tool [183], and the Venn diagrams to show the overlapping genes of different comparisons were made by an online tool (http:// bioinformatics.psb.ugent.be/webtools/Venn/). A cut-off value of the adjusted $p$-value (Padj) was used for the GO analysis. Fold changes $(\log 10)$ were used for representing in heat maps.

\section{Coverage analysis of $\mathrm{POCO} 1$}

The cDNA sequence of POCO1 was acquired from NCBI (https://www.ncbi.nlm.nih.gov/) (GenBank Accession: NM_101417.4) and imported to the CLC Genomics Workbench 7.5.1 program. The "Map reads to contigs" tool from the CLC Genomics Workbench 7.5.1 program was used to map reads in wild-type and pocol mutants ( $n=3$ for each genotype) to the reference gene (AT1G15480), and the read depth was examined. Visual inspection was obtained by the CLC Genomics Workbench 7.5.1 program.

The datasets supporting the conclusions of this article are included within the article and its additional files. 


\section{Supplementary information}

Supplementary information accompanies this paper at https://doi.org/10. 1186/s12870-020-02418-z.

\section{Additional file 1: Table S1, Table S2 and Table S3. List of}

differentially expressed genes. Differentially expressed genes in poco 1 in pre-inflorescence-inflorescence, inflorescence-flowering and inflorescenceinflorescence (fold changes either $\geq 2$ or $\leq-2$ FDR cutoff $<0.05$ ).

Additional file 2: Figure S1. GO enrichment terms. Top 5 molecular functions (GO:MF) and top 30 biological processes (GO:BP) for up- and down-regulated genes in pre-inflorescence-inflorescence, inflorescenceflowering and inflorescence-inflorescence are shown. The adjusted $p$ values (Padj) are shown in negative log10 scale.

Additional file 3: Figure S2. Expression of flowering-related genes affected by poco1. Heat map of flowering-related genes. Differentially expressed flowering genes in pocol versus wild-type in three comparisons are shown. Altered expression of flowering-related genes may explain the early-flowering phenotype of poco1. Fold changes (log10) were used for representing in the heat map. Red and blue represent up- and down-regulated transcripts respectively. Black represents that fold changes either $\geq 2$ or $\leq-2$ with an FDR $<0.05$ were not detected. Fold changes are relative to wild-type.

Additional file 4: Figure S3. poco 1 impaired $A B A$ signaling and response. Heat map of ABA-related differentially expressed genes. poco1 repressed numerous $A B A$-related genes, which results in $A B A$ signaling deficiency. Fold changes (log10) were used for representing in the heat map. Red and blue represent up- and down-regulated transcripts respectively. Black represents that fold changes either $\geq 2$ or $\leq-2$ with an FDR $<$ 0.05 were not detected. Fold changes are relative to wild-type.

Additional file 5: Figure S4. Fold change expression of drought and oxidative stress genes. Fold change heat map of the differentially expressed drought and oxidative stress-related genes in poco1. Fold changes (log10) were used for representing in the heat map. Red and blue represent up- and down-regulated transcripts respectively. Black represents that fold changes either $\geq 2$ or $\leq-2$ with an FDR $<0.05$ were not detected.

Additional file 6: Figure S5. Fold change heat map of genes encoding transcription factors. Fold change expression of genes encoding transcription factors is visualized by a heat map. The expression of different classes of transcription factors is affected in pocol. Fold changes (log10) were used for representing in the heat map. Red and blue represent up- and down-regulated transcripts respectively. Black represents that fold changes either $\geq 2$ or $\leq-2$ with an FDR $<0.05$ were not detected. TFs, transcription factors.

Additional file 7: Figure S6. Alteration of expression of genes associated with cellular signaling and mitochondrial perturbation targets in poco1. Genes associated with cellular signaling and mitochondrial perturbation were found differentially regulated in poco1. Fold changes (log10) were used for representing in the heat map. Red and blue represent up- and down-regulated transcripts respectively. Black represents that fold changes either $\geq 2$ or $\leq-2$ with an FDR $<0.05$ were not detected. Fold changes are relative to wild-type.

Additional file 8: Figure S7. Expression alteration in redox-related genes and genes associated with stomatal function. Genes associated with the redox status and stomatal function were found to have differential regulation in poco1. Fold changes ( $\log 10)$ were used for representing in heat maps. Red and blue represent up- and down-regulated transcripts respectively. Black represents that fold changes either $\geq 2$ or $\leq-2$ with an FDR $<0.05$ were not detected. Fold changes are relative to wild-type.

\section{Abbreviations}

ABA: Abscisic acid; ABFs: ABRE-binding factors; AREBs: ABRE-binding proteins; ABRE: ABA-responsive element; A. thaliana: Arabidopsis thaliana; FDR: False discovery rate; FT: FLOWERING LOCUS T; GO: Gene ontology; GRXs: Glutaredoxins; GSTs: Glutathione s-transferases; MAPKs: Mitogenactivated protein kinases; NGEMPs: Nuclear genes encoded mitochondrial proteins; POCO1: PRECOCIOUS1; PPR: Pentatricopeptide repeat; PYR1/PYL/ RCAR: Pyrabactin resistance 1/ PYR1-like/regulatory components of ABA receptors; ROS: Reactive oxygen species; RPKMs: Reads per kilobase per million mapped reads; SnRK2: Sucrose nonfermenting 1-related protein kinases 2; TF: Transcription factors; TRXs: Thioredoxin

\section{Acknowledgements}

Not applicable.

\section{Authors' contributions}

HE contributed to RNA sample preparation, analyzed RNA-seq data, interpreted results, wrote the manuscript, and designed figures; AK analyzed RNA-seq data, reviewed the manuscript, and aided with figure preparation; and FK conceived the study, reviewed the manuscript, and supervised the entire project. All authors approved the final manuscript.

\section{Funding}

Not applicable.

\section{Availability of data and materials}

The datasets generated and analyzed during the current study are available in the [ArrayExpress database at EMBL-EBI (www.ebi.ac.uk/arrayexpress)] repository under accession number E-MTAB-8912 (http://www.ebi.ac.uk/ arrayexpress/experiments/E-MTAB-8912/)

\section{Ethics approval and consent to participate}

Not applicable.

\section{Consent for publication}

Not applicable.

\section{Competing interests}

The authors declare that they have no competing interests.

\section{Author details}

${ }^{1}$ Department of Botany, Christian-Albrechts-University, Olshausenstr. 40, 24098 Kiel, Germany. ${ }^{2}$ Present address: Institute of Bioinformatics, International Technology Park, Bangalore 560066, India. ${ }^{3}$ Present address: Manipal Academy of Higher Education (MAHE), Manipal, Karnataka 576104, India.

Received: 29 November 2019 Accepted: 29 April 2020

Published online: 12 May 2020

\section{References}

1. Kim D-H, Doyle MR, Sung S, Amasino RM. Vernalization: winter and the timing of flowering in plants. Annu Rev Cell Dev Biol. 2009;25:277-99.

2. Kazan $\mathrm{K}$, Lyons $\mathrm{R}$. The link between flowering time and stress tolerance. J Exp Bot. 2016;67:47-60.

3. Cuming AC, Cho SH, Kamisugi Y, Graham H, Quatrano RS. Microarray analysis of transcriptional responses to abscisic acid and osmotic, salt, and drought stress in the moss, Physcomitrella patens. New Phytol. 2007;176: 275-87.

4. Finkelstein RR, Gampala SSL, Rock CD. Abscisic acid signaling in seeds and seedlings. Plant Cell. 2002;14:S15-45.

5. Hirayama T, Shinozaki K. Perception and transduction of abscisic acid signals: keys to the function of the versatile plant hormone ABA. Trends Plant Sci. 2007;12:343-51

6. Zhang J, Jia W, Yang J, Ismail AM. Role of ABA in integrating plant responses to drought and salt stresses. F Crop Res. 2006;97:111-9.

7. Sun Y, Harpazi B, Wijerathna-Yapa A, Merilo E, de Vries J, Michaeli D, et al. A ligand-independent origin of abscisic acid perception. Proc Natl Acad Sci U S A. 2019:116:24892-9.

8. Z Zhang H, Han W, De Smet I, Talboys P, Loya R, Hassan A, et al. ABA promotes quiescence of the quiescent Centre and suppresses stem cell differentiation in the Arabidopsis primary root meristem. Plant J. 2010;64: 764-74.

9. Ramachandran P, Wang G, Augstein F, De Vries J, Carlsbecker A. Continuous root xylem formation and vascular acclimation to water deficit involves endodermal ABA signalling via miR165. Dev. 2018:145:1-7.

10. Bloch D, Puli MR, Mosquna A, Yalovsky S. Abiotic stress modulates root patterning via ABA-regulated microRNA expression in the endodermis initials. 2019;146:dev177097. https://doi.org/10.1242/dev.177097. 
11. Verslues PE, Zhu J-K. New developments in abscisic acid perception and metabolism. Curr Opin Plant Biol. 2007;10:447-52.

12. Umezawa T, Nakashima K, Miyakawa T, Kuromori T, Tanokura M, Shinozaki K, et al. Molecular basis of the core regulatory network in ABA responses: sensing, signaling and transport. Plant Cell Physiol. 2010;51:1821-39.

13. Yoshida T, Mogami J, Yamaguchi-Shinozaki K. ABA-dependent and ABAindependent signaling in response to osmotic stress in plants. Curr Opin Plant Biol. 2014;21:133-9.

14. Jaradat MR, Feurtado J, Huang D, Lu Y, Cutler AJ. Multiple roles of the transcription factor AtMYBR1/AtMYB44 in ABA signaling, stress responses, and leaf senescence. BMC Plant Biol. 2013;13:192.

15. Choi H, Hong J, Ha J, Kang J, Kim SY. ABFs, a family of ABA-responsive element binding factors. J Biol Chem. 2000;275:1723-30.

16. Uno Y, Furihata T, Abe H, Yoshida R, Shinozaki K, Yamaguchi-Shinozaki K. Arabidopsis basic leucine zipper transcription factors involved in an abscisic acid-dependent signal transduction pathway under drought and highsalinity conditions. Proc Natl Acad Sci. 2000;97:11632-7.

17. Domagalska MA, Sarnowska E, Nagy F, Davis SJ. Genetic analyses of interactions among gibberellin, abscisic acid, and brassinosteroids in the control of flowering time in Arabidopsis thaliana. PLoS One. 2010;5:e14012.

18. Wang $Y, L i L, Y e T$, Lu $Y$, Chen $X, W u Y$. The inhibitory effect of $A B A$ on floral transition is mediated by ABI5 in Arabidopsis. J Exp Bot. 2013; 64:675-84.

19. Helliwell CA, Wood CC, Robertson M, James Peacock W, Dennis ES. The Arabidopsis FLC protein interacts directly in vivo with SOC1 and FT chromatin and is part of a high-molecular-weight protein complex. Plant J. 2006:46:183-92.

20. Vanlerberghe GC. Alternative oxidase: a mitochondrial respiratory pathway to maintain metabolic and signaling homeostasis during abiotic and biotic stress in plants. Int J Mol Sci. 2013;14:6805-47.

21. Skinner DJ, Baker SC, Meister RJ, Broadhvest J, Schneitz K, Gasser CS. The Arabidopsis HUELLENLOS gene, which is essential for normal ovule development, encodes a mitochondrial ribosomal protein. Plant Cell. 2001; 13:2719-30.

22. Landschütze $V$, Willmitzer $L$, Müller-Röber B. Inhibition of flower formation by antisense repression of mitochondrial citrate synthase in transgenic potato plants leads to a specific disintegration of the ovary tissues of flowers. EMBO J. 1995;14:660-6.

23. Ng S, De Clercq I, Van Aken O, Law SR, Ivanova A, Willems P, et al. Anterograde and retrograde regulation of nuclear genes encoding mitochondrial proteins during growth, development, and stress. Mol Plant. 2014;7:1075-93.

24. Foyer $\mathrm{CH}$, Noctor $\mathrm{G}$. Redox sensing and signalling associated with reactive oxygen in chloroplasts, peroxisomes and mitochondria. Physiol Plant. 2003; 119:355-64.

25. Zsigmond L, Rigo G, Szarka A, Szekely G, Otvos K, Darula Z, et al. Arabidopsis PPR40 connects abiotic stress responses to mitochondrial electron transport. Plant Physiol. 2008;146:1721-37.

26. Kmiecik $\mathrm{P}$, Leonardelli $\mathrm{M}$, Teige $\mathrm{M}$. Novel connections in plant organellar signalling link different stress responses and signalling pathways. J Exp Bot. 2016;67:3793-807.

27. Emami H, Kempken F. PRECOCIOUS 1(POCO1), a mitochondrial pentatricopeptide repeat protein affects flowering time in Arabidopsis thaliana. Plant J. 2019;100:265-78.

28. Lurin C, Andrés C, Aubourg S, Bellaoui M, Bitton F, Bruyère C, et al. Genomewide analysis of Arabidopsis pentatricopeptide repeat proteins reveals their essential role in organelle biogenesis. Plant Cell. 2004;16:2089-103.

29. OToole N, Hattori M, Andres C, lida K, Lurin C, Schmitz-Linneweber C, et al. On the expansion of the pentatricopeptide repeat gene family in plants. Mol Biol Evol. 2008:25:1120-8.

30. Akhter S, Uddin MN, Jeong IS, Kim DW, Liu XM, Bahk JD. Role of Arabidopsis AtPI4KY3, a type II phosphoinositide 4-kinase, in abiotic stress responses and floral transition. Plant Biotechnol J. 2016;14:215-30.

31. Islam MM, Tani C, Watanabe-Sugimoto M, Uraji M, Jahan MS, Masuda C, et al. Myrosinases, TGG1 and TGG2, redundantly function in ABA and MeJA signaling in Arabidopsis guard cells. Plant Cell Physiol. 2009:50:1171-5.

32. Gehring C, Paolocci F, Alqurashi M, Lilley K, Bianchet C, Chiapello M. Early responses to severe drought stress in the Arabidopsis thaliana cell suspension culture proteome. Proteomes. 2018;6:38.

33. Torti S, Fornara F, Vincent C, Andrés F, Nordström K, Göbel U, et al. Analysis of the Arabidopsis shoot meristem transcriptome during floral transition identifies distinct regulatory patterns and a leucine-rich repeat protein that promotes flowering. Plant Cell. 2012;24:444-62.

34. Idänheimo N. The role of cysteine-rich receptor-like protein kinases in ROS signaling in Arabidopsis thaliana. Finland: University of Helsinki; 2015.

35. Lin K, Zhao H, Gan S, Li G. Arabidopsis ELF4-like proteins EFL1 and EFL3 influence flowering time. Gene. 2019;700:131-8.

36. Borner R, Kampmann G, Apel K, Melzer S. The FPF gene family and flowering time control in Arabidopsis. 11TH Int Conf Arab Res. 2000. https:// doi.org/10.2172/807954.

37. Wang J, Tian L, Lee H-S, Chen ZJ. Nonadditive regulation of FRI and FLC loci mediates flowering-time variation in Arabidopsis allopolyploids. Genetics. 2006;173:965-74.

38. Quesada V, Dean C, Simpson GG. Regulated RNA processing in the control of Arabidopsis flowering. Int J Dev Biol. 2005;49:773-80.

39. Choi K, Kim J, Hwang H-J, Kim S, Park C, Kim SY, et al. The FRIGIDA complex activates transcription of $F L C$, a strong flowering repressor in Arabidopsis, by recruiting chromatin modification factors. Plant Cell. 2011;23:289-303.

40. Michaels SD, Bezerra IC, Amasino RM. FRIGIDA-related genes are required for the winter-annual habit in Arabidopsis. Proc Natl Acad Sci U S A. 2004; 101:3281-5

41. Koornneef M, Hanhart CJ, van der Veen JH. A genetic and physiological analysis of late flowering mutants in Arabidopsis thaliana. Mol Gen Genet MGG. 1991;229:57-66.

42. Chiang HH, Hwang I, Goodman HM. Isolation of the Arabidopsis GA4 locus. Plant Cell. 1995;7:195-201.

43. Sun T. Gibberellin metabolism, perception and signaling pathways in Arabidopsis. Arab B. 2008;6:e0103.

44. Rédei GP. Supervital mutants of Arabidopsis. Genetics. 1962;47:443-60.

45. Griffiths J, Murase K, Rieu I, Zentella R, Zhang Z-L, Powers SJ, et al. Genetic characterization and functional analysis of the GID1 gibberellin receptors in Arabidopsis. Plant Cell. 2006;18:3399-414.

46. Streitner C, Danisman S, Wehrle F, Schöning JC, Alfano JR, Staiger D. The small glycine-rich RNA binding protein AtGRP7 promotes floral transition in Arabidopsis thaliana. Plant J. 2008;56:239-50.

47. Boss PK, Bastow RM, Mylne JS, Dean C. Multiple pathways in the decision to flower: enabling, promoting, and resetting. Plant Cell. 2004:16:S18-31.

48. Halliday KJ, Salter MG, Thingnaes E, Whitelam GC. Phytochrome control of flowering is temperature sensitive and correlates with expression of the floral integrator FT. Plant J. 2003;33:875-85.

49. Xing S, Zachgo S. ROXY1 and ROXY2, two Arabidopsis glutaredoxin genes, are required for anther development. Plant J. 2008;53:790-801.

50. Leung J, Merlot S, Giraudat J. The Arabidopsis ABSCISIC ACID-INSENSITIVE2 $(A B / 2)$ and $A B / 1$ genes encode homologous protein phosphatases $2 C$ involved in abscisic acid signal transduction. Plant Cell. 1997;9:759-71.

51. Kulik A, Wawer I, Krzywińska E, Bucholc M, Dobrowolska G. SnRK2 protein kinases - key regulators of plant response to abiotic stresses. Omi A J Integr Biol. 2011;15:859-72.

52. Kang J, Choi H, Im M, Kim SY. Arabidopsis basic leucine zipper proteins that mediate stress-responsive abscisic acid signaling. Plant Cell. 2002;14:343-57.

53. Hwang K, Susila H, Nasim Z, Jung J-Y, Ahn JH. Arabidopsis ABF3 and ABF4 transcription factors act with the NF-YC complex to regulate $\mathrm{SOC1}$ expression and mediate drought-accelerated flowering. Mol Plant. 2019;12: 489-505.

54. Cheng S-H, Willmann M, Chen $\mathrm{H}$, Sheen J. Calcium signaling through protein kinases. The Arabidopsis calcium-dependent protein kinase gene family. Plant Physiol. 2002;129:469-85.

55. Antoni R, Rodriguez L, Gonzalez-Guzman M, Pizzio GA, Rodriguez PL. News on ABA transport, protein degradation, and ABFs/WRKYs in ABA signaling. Curr Opin Plant Biol. 2011;14:547-53.

56. Kuhn JM, Boisson-Dernier A, Dizon MB, Maktabi MH, Schroeder Jl. The protein phosphatase AtPP2CA negatively regulates abscisic acid signal transduction in Arabidopsis, and effects of abhl on AtPP2CA mRNA. Plant Physiol. 2006;140:127-39

57. Yoshida T, Nishimura N, Kitahata N, Kuromori T, Ito T, Asami T, et al. ABAHypersensitive Germination3 encodes a protein phosphatase 2C (AtPP2CA) that strongly regulates abscisic acid signaling during germination among Arabidopsis protein phosphatase 2Cs. Plant Physiol. 2006;140:115-26.

58. Choi H, Park H, Park JH, Kim S, Im M, Seo H, et al. Arabidopsis calciumdependent protein kinase AtCPK32 interacts with ABF4, a transcriptional regulator of abscisic acid-responsive gene expression, and modulates its activity. Plant Physiol. 2005;139:1750-61. 
59. Umezawa T, Okamoto M, Kushiro T, Nambara E, Oono Y, Seki M, et al. CYP707A3, a major ABA 8'-hydroxylase involved in dehydration and rehydration response in Arabidopsis thaliana. Plant J. 2006;46:171-82.

60. Guo L, Yang H, Zhang X, Yang S. Lipid transfer protein 3 as a target of MYB96 mediates freezing and drought stress in Arabidopsis. J Exp Bot. 2013; 64:1755-67.

61. Deeken R, Saupe S, Klinkenberg J, Riedel M, Leide J, Hedrich R, et al. The nonspecific lipid transfer protein AtLtpl-4 is involved in suberin formation of Arabidopsis thaliana crown galls. Plant Physiol. 2016;172:1911-27.

62. He Y, Gan S. A novel zinc-finger protein with a proline-rich domain mediates ABA-regulated seed dormancy in Arabidopsis. Plant Mol Biol. 2004; 54:1-9.

63. Wang $Y$, Yang $L$, Chen $X$, Ye T, Zhong B, Liu R, et al. Major latex protein-like protein 43 (MLP43) functions as a positive regulator during abscisic acid responses and confers drought tolerance in Arabidopsis thaliana. J Exp Bot. 2016;67:421-34.

64. Gonzalez-Jorge S, Ha S-H, Magallanes-Lundback M, Gilliland LU, Zhou A, Lipka AE, et al. CAROTENOID CLEAVAGE DIOXYGENASE4 is a negative regulator of $\beta$-carotene content in Arabidopsis seeds. Plant Cell. 2013;25: 4812-26.

65. Ma Y, Szostkiewicz I, Korte A, Moes D, Yang Y, Christmann A, et al. Regulators of PP2C phosphatase activity function as abscisic acid sensors. Science. 2009;324:1064-8.

66. Zhao Y, Chan Z, Gao J, Xing L, Cao M, Yu C, et al. ABA receptor PYL9 promotes drought resistance and leaf senescence. Proc Natl Acad Sci. 2016; 113:1949-54.

67. Osakabe Y, Maruyama K, Seki M, Satou M, Shinozaki K, Yamaguchi-Shinozaki K. Leucine-rich repeat receptor-like kinase1 is a key membrane-bound regulator of abscisic acid early signaling in Arabidopsis. Plant Cell. 2005;17: 1105-19.

68. Sharma M, Pandey GK. Expansion and function of repeat domain proteins during stress and development in plants. Front Plant Sci. 2016;6:1-15.

69. Umezawa T, Yoshida R, Maruyama K, Yamaguchi-Shinozaki K, Shinozaki K. SRK2C, a SNF1-related protein kinase 2, improves drought tolerance by controlling stress-responsive gene expression in Arabidopsis thaliana. Proc Natl Acad Sci. 2004;101:17306-11.

70. Sokolovski S, Hills A, Gay RA, Blatt MR. Functional interaction of the SNARE protein NtSyp121 in Ca2+ channel gating, Ca2+ transients and ABA signalling of stomatal guard cells. Mol Plant. 2008;1:347-58.

71. Luan S. Protein phosphatases in plants. Annu Rev Plant Biol. 2003;54:63-92.

72. Yoshida T, Fujita Y, Sayama H, Kidokoro S, Maruyama K, Mizoi J, et al. AREB1, $A R E B 2$, and $A B F 3$ are master transcription factors that cooperatively regulate ABRE-dependent ABA signaling involved in drought stress tolerance and require ABA for full activation. Plant J. 2010;61:672-85.

73. Lang V, Palva ET. The expression of a Rab-related gene, rab18, is induced by abscisic acid during the cold acclimation process of Arabidopsis thaliana ( $\mathrm{L}$.) Heynh. Plant Mol Biol. 1992;20:951-62.

74. Yamaguchi-Shinozaki K, Shinozaki K. A novel cis-acting element in an Arabidopsis gene is involved in responsiveness to drought, lowtemperature, or high-salt stress. Plant Cell. 1994;6:251-64.

75. Guo W, Ward RW, Thomashow MF. Characterization of a cold-regulated wheat gene related to Arabidopsis cor47. Plant Physiol. 1992;100:915-22.

76. Breton G, Danyluk J, Charron J-BF, Sarhan F. Expression profiling and bioinformatic analyses of a novel stress-regulated multispanning transmembrane protein family from cereals and Arabidopsis. Plant Physiol. 2003;132:64-74

77. Tran L-SP, Nakashima K, Sakuma Y, Simpson SD, Fujita Y, Maruyama K, et al. Isolation and functional analysis of Arabidopsis stress-inducible NAC transcription factors that bind to a drought-responsive cis-element in the early responsive to dehydration stress 1 promoter. Plant Cell. 2004;16:2481-98.

78. Kim SY, Nam KH. Physiological roles of ERD10 in abiotic stresses and seed germination of Arabidopsis. Plant Cell Rep. 2010;29:203-9.

79. Arondel V, Vergnolle C, Cantrel C, Kader J-C. Lipid transfer proteins are encoded by a small multigene family in Arabidopsis thaliana. Plant Sci. 2000; 157:1-12.

80. Jain A, Wilson GT, Connolly EL. The diverse roles of FRO family metalloreductases in iron and copper homeostasis. Front Plant Sci. 2014;5: 100. https://doi.org/10.3389/fpls.2014.00100.

81. Yamaguchi-Shinozaki K, Shinozaki K. Characterization of the expression of a desiccation-responsive $r d 29$ gene of Arabidopsis thaliana and analysis of its promoter in transgenic plants. Mol Gen Genet MGG. 1993;236-236:331-40.
82. Ådén J, Wallgren M, Storm P, Weise CF, Christiansen A, Schröder WP, et al Extraordinary $\mu \mathrm{s}-\mathrm{ms}$ backbone dynamics in Arabidopsis thaliana peroxiredoxin Q. Biochim Biophys Acta. 2011;1814:1880-90.

83. Kiddle G, Pastori GM, Bernard S, Pignocchi C, Antoniw J, Verrier PJ, et al. Effects of leaf ascorbate content on defense and photosynthesis gene expression in Arabidopsis thaliana. Antioxid Redox Signal. 2003;5:23-32.

84. Alexandersson E, Fraysse L, Sjövall-Larsen S, Gustavsson S, Fellert M, Karlsson $\mathrm{M}$, et al. Whole gene family expression and drought stress regulation of Aquaporins. Plant Mol Biol. 2005;59:469-84.

85. Ito S, Song YH, Josephson-Day AR, Miller RJ, Breton G, Olmstead RG, et al. FLOWERING BHLH transcriptional activators control expression of the photoperiodic flowering regulator CONSTANS in Arabidopsis. Proc Natl Acad Sci. 2012;109:3582-7.

86. Lee S, Lee S, Yang KY, Kim YM, Park SY, Kim SY, et al. Overexpression of PRE1 and its homologous genes activates gibberellin-dependent responses in Arabidopsis thaliana. Plant Cell Physiol. 2006;47:591-600.

87. Abe H, Urao T, Ito T, Seki M, Shinozaki K, Yamaguchi-Shinozaki K. Arabidopsis AtMYC2 (bHLH) and AtMYB2 (MYB) function as transcriptional activators in abscisic acid signaling. Plant Cell. 2003;15:63-78.

88. Lindemose S, O'Shea C, Jensen MK, Skriver K. Structure, function and networks of transcription factors involved in abiotic stress responses. Int J Mol Sci. 2013;14:5842-78.

89. Cui MH, Yoo KS, Hyoung S, Nguyen HTK, Kim YY, Kim HJ, et al. An Arabidopsis R2R3-MYB transcription factor, AtMYB20, negatively regulates type $2 \mathrm{C}$ serine/threonine protein phosphatases to enhance salt tolerance. FEBS Lett. 2013;587:1773-8.

90. Preston J, Wheeler J, Heazlewood J, Li SF, Parish RW. AtMYB32 is required for normal pollen development in Arabidopsis thaliana. Plant J. 2004;40:97995.

91. Jung C, Jun SS, Sang WH, Yeon JK, Chung HK, Sang IS, et al. Overexpression of AtMYB44 enhances stomatal closure to confer abiotic stress tolerance in transgenic Arabidopsis. Plant Physiol. 2008;146:623-35.

92. Frerigmann H, Gigolashvili T. MYB34, MYB51, and MYB122 distinctly regulate Indolic Glucosinolate biosynthesis in Arabidopsis thaliana. Mol Plant. 2014;7: 814-28

93. Zhao $Y$, Xing $L$, Wang $X$, Hou $Y$-J, Gao J, Wang $P$, et al. The ABA receptor PYL8 promotes lateral root growth by Enhancing MYB77-dependent transcription of auxin-responsive genes. Sci Signal. 2014;7:ra53.

94. Li JQ, Zhang J, Wang XC, Chen J. A membrane-tethered transcription factor ANAC089 negatively regulates floral initiation in Arabidopsis thaliana. Sci China Life Sci. 2010;53:1299-306.

95. Matías-Hernández L, Aguilar-Jaramillo AE, Marín-González E, Suárez-López P, Pelaz S. RAV genes: regulation of floral induction and beyond. Ann Bot. 2014;114:1459-70.

96. Eulgem T, Rushton PJ, Robatzek S, Somssich IE. The WRKY superfamily of plant transcription factors. Trends Plant Sci. 2000;5:199-206.

97. Vanderauwera S, Vandenbroucke $K$, Inze A, van de Cotte B, Muhlenbock P, De Rycke R, et al. AtWRKY15 perturbation abolishes the mitochondrial stress response that steers osmotic stress tolerance in Arabidopsis. Proc Natl Acad Sci. 2012;109:20113-8.

98. Bakshi M, Oelmüller R. WRKY transcription factors. Plant Signal Behav. 2014; 9:e27700.

99. Jiang $Y$, Deyholos MK. Functional characterization of Arabidopsis $\mathrm{NaCl}$ inducible WRKY25 and WRKY33 transcription factors in abiotic stresses. Plant Mol Biol. 2009;69:91-105.

100. Rushton DL, Tripathi P, Rabara RC, Lin J, Ringler P, Boken AK, et al. WRKY transcription factors: key components in abscisic acid signalling. Plant Biotechnol J. 2012;10:2-11.

101. Ding ZJ, Yan JY, Li CX, Li GX, Wu YR, Zheng SJ. Transcription factor WRKY46 modulates the development of Arabidopsis lateral roots in osmotic/salt stress conditions via regulation of ABA signaling and auxin homeostasis. Plant J. 2015:84:56-69.

102. Shinozaki K, Yamaguchi-Shinozaki K, Seki M. Regulatory network of gene expression in the drought and cold stress responses. Curr Opin Plant Biol. 2003;6:410-7.

103. Kleine T, Leister D. Retrograde signaling: organelles go networking. Biochim Biophys Acta Bioenerg. 1857;2016:1313-25.

104. He Y, Zhou J, Shan L, Meng X. Plant cell surface receptor-mediated signaling - a common theme amid diversity. J Cell Sci. 2018;131:jcs209353.

105. Rhoads DM, Subbaiah CC. Mitochondrial retrograde regulation in plants. Mitochondrion. 2007;7:177-94. 
106. Taylor NL, Day DA, Millar AH. Environmental stress causes oxidative damage to plant mitochondria leading to inhibition of glycine decarboxylase. J Biol Chem. 2002;277:42663-8.

107. Van Aken O, Giraud E, Clifton R, Whelan J. Alternative oxidase: a target and regulator of stress responses. Physiol Plant. 2009;137:354-61.

108. Berkowitz O, De Clercq I, Van Breusegem F, Whelan J. Interaction between hormonal and mitochondrial signalling during growth, development and in plant defence responses. Plant Cell Environ. 2016;39:1127-39.

109. Lama S, Broda M, Abbas Z, Vaneechoutte D, Belt K, Säll T, et al. Neofunctionalization of mitochondrial proteins and incorporation into signaling networks in plants. Mol Biol Evol. 2019;36:974-89.

110. Van Aken O, Ford E, Lister R, Huang S, Millar AH. Retrograde signalling caused by heritable mitochondrial dysfunction is partially mediated by ANAC017 and improves plant performance. Plant J. 2016;88:542-58.

111. Clifton R, Millar AH, Whelan J. Alternative oxidases in Arabidopsis: a comparative analysis of differential expression in the gene family provides new insights into function of non-phosphorylating bypasses. Biochim Biophys Acta Bioenerg. 2006;1757:730-41.

112. De Clercq I, Vermeirssen V, Van Aken O, Vandepoele K, Murcha MW, Law SR, et al. The membrane-bound NAC transcription factor ANAC013 functions in mitochondrial retrograde regulation of the oxidative stress response in Arabidopsis. Plant Cell. 2013;25:3472-90.

113. Nakashima K, Satoh R, Kiyosue T, Yamaguchi-Shinozaki K, Shinozaki K. A gene encoding proline dehydrogenase is not only induced by proline and hypoosmolarity, but is also developmentally regulated in the reproductive organs of Arabidopsis. Plant Physiol. 1998;118:1233-41.

114. Noctor G, De Paepe R, Foyer CH. Mitochondrial redox biology and homeostasis in plants. Trends Plant Sci. 2007;12:125-34.

115. Rouhier N, Vlamis-Gardikas A, Lillig CH, Berndt C, Schwenn J-D, Holmgren A et al. Characterization of the redox properties of poplar glutaredoxin. Antioxid Redox Signal. 2003;5:15-22.

116. Dixon DP, Hawkins T, Hussey PJ, Edwards R. Enzyme activities and subcellular localization of members of the Arabidopsis glutathione transferase superfamily. J Exp Bot. 2009;60:1207-18.

117. Horváth E, Bela K, Papdi C, Gallé Á, Szabados L, Tari I, et al. The role of Arabidopsis glutathione transferase F9 gene under oxidative stress in seedlings. Acta Biol Hung. 2015;66:406-18.

118. Kitamura S, Akita Y, Ishizaka H, Narumi I, Tanaka A. Molecular characterization of an anthocyanin-related glutathione S-transferase gene in cyclamen. J Plant Physiol. 2012;169:636-42.

119. Park S-W, Li W, Viehhauser A, He B, Kim S, Nilsson AK, et al. Cyclophilin 20-3 relays a 12-oxo-phytodienoic acid signal during stress responsive regulation of cellular redox homeostasis. Proc Natl Acad Sci. 2013;110:9559-64.

120. Gutsche N, Thurow C, Zachgo S, Gatz C. Plant-specific CC-type glutaredoxins: functions in developmental processes and stress responses. Biol Chem. 2015;396:495-509.

121. Li N, Muthreich M, Huang L, Thurow C, Sun T, Zhang Y, et al. TGACGBINDING FACTORs (TGAs) and TGA-interacting CC-type glutaredoxins modulate hyponastic growth in Arabidopsis thaliana. New Phytol. 2019;221: 1906-18.

122. Ota R, Ohkubo Y, Yamashita Y, Ogawa-Ohnishi M, Matsubayashi Y. Shoot-toroot mobile CEPD-like 2 integrates shoot nitrogen status to systemically regulate nitrate uptake in Arabidopsis. Nat Commun. 2020;11:641.

123. Rouhier N. Genome-wide analysis of plant glutaredoxin systems. J Exp Bot. 2006;57:1685-96

124. Wimmelbacher M, Börnke F. Redox activity of thioredoxin $z$ and fructokinase-like protein 1 is dispensable for autotrophic growth of Arabidopsis thaliana. J Exp Bot. 2014;65:2405-13.

125. Laloi C, Mestres-Ortega D, Marco Y, Meyer Y, Reichheld J-P. The Arabidopsis cytosolic thioredoxin $\mathrm{h} 5$ gene induction by oxidative stress and its W-boxmediated response to pathogen elicitor. Plant Physiol. 2004;134:1006-16.

126. Jha SK, Sharma M, Pandey GK. Role of cyclic nucleotide gated channels in stress management in plants. Curr Genomics. 2016;17:315-29.

127. Kwak JM, Nguyen $V$, Schroeder Jl. The role of reactive oxygen species in hormonal responses. Plant Physiol. 2006;141:323-9.

128. Pei Z-M, Murata Y, Benning G, Thomine S, Klüsener B, Allen GJ, et al. Calcium channels activated by hydrogen peroxide mediate abscisic acid signalling in guard cells. Nature. 2000;406:731-4.

129. Askari-Khorsgani O, Flores FB, Pessarakli M. Plant signaling pathways involved in stomatal movement under drought stress conditions. Adv Plants Agric Res. 2018:8:290-7.
130. Kim JS, Jung HJ, Lee HJ, Kim KA, Goh CH, Woo Y, et al. Glycine-rich RNAbinding protein7 affects abiotic stress responses by regulating stomata opening and closing in Arabidopsis thaliana. Plant J. 2008:55:455-66.

131. Roelfsema MRG, Prins HBA. Effect of abscisic acid on stomatal opening in isolated epidermal strips of abi mutants of Arabidopsis thaliana. Physiol Plant. 1995;95:373-8.

132. Pei ZM, Kuchitsu K, Ward JM, Schwarz M, Schroeder JI. Differential abscisic acid regulation of guard cell slow anion channels in Arabidopsis wild-type and abil and abi2 mutants. Plant Cell. 1997:9:409-23.

133. Wang YF, Munemasa S, Nishimura N, Ren HM, Robert N, Han M, et al. Identification of cyclic GMP-activated nonselective Ca2+-permeable cation channels and associated CNGC5 and CNGC6 genes in Arabidopsis guard cells. Plant Physiol. 2013;163:578-90.

134. Osakabe Y, Mizuno S, Tanaka H, Maruyama K, Osakabe K, Todaka D, et al. Overproduction of the membrane-bound receptor-like protein kinase 1 , RPK1, enhances abiotic stress tolerance in Arabidopsis. J Biol Chem. 2010; 285:9190-201.

135. Barth C, Jander G. Arabidopsis myrosinases TGG1 and TGG2 have redundant function in glucosinolate breakdown and insect defense. Plant J. 2006:46: 549-62.

136. Zhao Z, Zhang W, Stanley BA, Assmann SM. Functional proteomics of Arabidopsis thaliana guard cells uncovers new stomatal signaling pathways. Plant Cell. 2008;20:3210-26.

137. Halkier BA, Gershenzon J. Biology and biochemistry of glucosinolates. Annu Rev Plant Biol. 2006:57:303-33.

138. Deshpande S, James A, Franklin C, Leach L, Yang J. Identification of novel flowering genes using RNA-Seq pipeline employing combinatorial approach in Arabidopsis thaliana time-series apical shoot meristem. Int J Bioinform Res Appl. 2017; in press.

139. Harb A, Krishnan A, Ambavaram MMR, Pereira A. Molecular and physiological analysis of drought stress in Arabidopsis reveals early responses leading to acclimation in plant growth. Plant Physiol. 2010;154: 1254-71.

140. Näsholm T, Kielland K, Ganeteg U. Uptake of organic nitrogen by plants. New Phytol. 2009;182:31-48.

141. Rentsch D, Schmidt S, Tegeder M. Transporters for uptake and allocation of organic nitrogen compounds in plants. FEBS Lett. 2007;581:2281-9.

142. Vidal EA, Moyano TC, Canales J, Gutiérrez RA. Nitrogen control of developmental phase transitions in Arabidopsis thaliana. J Exp Bot. 2014;65: 5611-8.

143. Weber K, Burow M. Nitrogen - essential macronutrient and signal controlling flowering time. Physiol Plant. 2018;162:251-60.

144. Yuan S, Zhang Z-W, Zheng C, Zhao Z-Y, Wang Y, Feng L-Y, et al. Arabidopsis cryptochrome 1 functions in nitrogen regulation of flowering. Proc Natl Acad Sci. 2016:113:7661-6.

145. Pigliucci M, Schlichting CD. Reaction norms of Arabidopsis (Brassicaceae). III. Response to nutrients in 26 populations from a worldwide collection. Am J Bot. 1995;82:1117-25.

146. Marín IC, Loef I, Bartetzko L, Searle I, Coupland G, Stitt M, et al. Nitrate regulates floral induction in Arabidopsis, acting independently of light, gibberellin and autonomous pathways. Planta. 2011;233:539-52

147. Teng $Y$, Liang $Y$, Wang M, Mai H, Ke L. Nitrate Transporter 1.1 is involved in regulating flowering time via transcriptional regulation of FLOWERING LOCUS C in Arabidopsis thaliana. Plant Sci. 2019;284:30-6.

148. Riboni M, Galbiati M, Tonelli C, Conti L. GIGANTEA enables drought escape response via abscisic acid-dependent activation of the florigens and SUPPRESSOR OF OVEREXPRESSION OF CONSTANS1. Plant Physiol. 2013;162: 1706-19.

149. Takeno K. Stress-induced flowering: the third category of flowering response. J Exp Bot. 2016;67:4925-34

150. Xiao J, Li C, Xu S, Xing L, XU Y, Chong K. JACALIN-LECTIN LIKE1 regulates the nuclear PROTEIN7, influencing the RNA processing of accumulation of GLYCINE-RICH RNA-BINDING FLOWERING LOCUS C antisense transcripts and flowering time in Arabidopsis. Plant Physiol. 2015;169:2102-17.

151. Song $Y$ H, Ito $S$, Imaizumi T. Flowering time regulation : photoperiod- and temperature-sensingin leaves. Trends Plant Sci. 2013;18:575-83.

152. Kania T, Russenberger D, Peng S, Apel K, Melzer S. FPF1 promotes flowering in Arabidopsis. Plant Cell. 1997;9:1327-38.

153. Yamaguchi-Shinozaki K, Shinozaki K. Organization of cis-acting regulatory elements in osmotic- and cold-stress-responsive promoters. Trends Plant Sci. 2005;10:88-94 
154. Yasuda M, Ishikawa A, Jikumaru Y, Seki M, Umezawa T, Asami T, et al. Antagonistic interaction between systemic acquired resistance and the abscisic acid-mediated abiotic stress response in Arabidopsis. Plant Cell. 2008;20:1678-92.

155. Ton J, Flors V, Mauch-Mani B. The multifaceted role of ABA in disease resistance. Trends Plant Sci. 2009;14:310-7.

156. Cao M-J, Zhang Y-L, Liu X, Huang H, Zhou XE, Wang W-L, et al. Combining chemical and genetic approaches to increase drought resistance in plants. Nat Commun. 2017;8:1183.

157. Himmelbach A, Yang Y, Grill E. Relay and control of abscisic acid signaling Curr Opin Plant Biol. 2003;6:470-9.

158. Yoshida R, Hobo T, Ichimura K, Mizoguchi T, Takahashi F, Aronso J, et al. ABA-activated SnRK2 protein kinase is required for dehydration stress signaling in Arabidopsis. Plant Cell Physiol. 2002;43:1473-83.

159. Mittler R, Blumwald E. The roles of ROS and ABA in systemic acquired acclimation. Plant Cell. 2015;27:64-70.

160. Nakano T, Suzuki K, Fujimura T, Shinshi H. Genome-wide analysis of the ERF gene family in Arabidopsis and Rice. Plant Physiol. 2006;140:411-32.

161. Chao Y, Zhang T, Yang Q, Kang J, Sun Y, Gruber MY, et al. Expression of the alfalfa CCCH-type zinc finger protein gene MsZFN delays flowering time in transgenic Arabidopsis thaliana. Plant Sci. 2014;215-216:92-9.

162. Kim S, Choi K, Park C, Hwang H-J, Lee I. SUPPRESSOR OF FRIGIDA4, encoding a $\mathrm{C} 2 \mathrm{H} 2$-type zinc finger protein, represses flowering by transcriptional activation of Arabidopsis FLOWERING LOCUS C. Plant Cell. 2006;18:2985-98.

163. Yoo SY, Kim Y, Kim SY, Lee JS, Ahn JH. Control of flowering time and cold response by a NAC-domain protein in Arabidopsis. PLoS One. 2007;2:e642.

164. Jonak C, Okrész L, Bögre L, Hirt H. Complexity, cross talk and integration of plant MAP kinase signalling. Curr Opin Plant Biol. 2002;5:415-24.

165. Fujita M, Fujita Y, Noutoshi Y, Takahashi F, Narusaka Y, Yamaguchi-Shinozaki $K$, et al. Crosstalk between abiotic and biotic stress responses: a current view from the points of convergence in the stress signaling networks. Curr Opin Plant Biol. 2006;9:436-42.

166. Zhang T, Liu Y, Yang T, Zhang L, Xu S, Xue L, et al. Diverse signals converge at MAPK cascades in plant. Plant Physiol Biochem. 2006;44:274-83.

167. Tör M, Lotze MT, Holton N. Receptor-mediated signalling in plants: molecular patterns and programmes. J Exp Bot. 2009;60:3645-54.

168. Rhoads DM, Umbach AL, Subbaiah CC, Siedow JN. Mitochondrial reactive oxygen species. Contribution to oxidative stress and interorganellar signaling. Plant Physiol. 2006;141:357-66.

169. Schwarzländer $M$, Finkemeier I. Mitochondrial energy and redox signaling in plants. Antioxid Redox Signal. 2013;18:2122-44.

170. Schwarzländer M, König AC, Sweetlove $L$, Finkemeier I. The impact of impaired mitochondrial function on retrograde signalling: a meta-analysis of transcriptomic responses. J Exp Bot. 2012;63:1735-50.

171. Jiang H-W, Liu M-J, Chen I-C, Huang C-H, Chao L-Y, Hsieh H-L. A glutathione $\mathrm{s}$-transferase regulated by light and hormones participates in the modulation of Arabidopsis seedling development. Plant Physiol. 2010;154: $1646-58$.

172. Mang HG, Kang EO, Shim JH, Kim S, Park KY, Kim YS, et al. A proteomic analysis identifies glutathione s-transferase isoforms whose abundance is differentially regulated by ethylene during the formation of early root epidermis in Arabidopsis seedlings. Biochim Biophys Acta. 2004;1676:231-9.

173. Sinha R, Kumar D, Datta R, Hazra S, Bhattacharyya D, Mazumdar AB, et al. Integrated transcriptomic and proteomic analysis of Arabidopsis thaliana exposed to glutathione unravels its role in plant defense. Plant Cell Tissue Organ Cult. 2015;120:975-88.

174. Chen J-H, Jiang H-W, Hsieh E-J, Chen H-Y, Chien C-T, Hsieh H-L, et al. Drought and salt stress tolerance of an Arabidopsis glutathione s-transferase u17 knockout mutant are attributed to the combined effect of glutathione and abscisic acid. Plant Physiol. 2012;158:340-51.

175. Thompson AJ, Andrews J, Mulholland BJ, McKee JMT, Hilton HW, Horridge $J S$, et al. Overproduction of abscisic acid in tomato increases transpiration efficiency and root hydraulic conductivity and influences leaf expansion. Plant Physiol. 2007;143:1905-17.

176. Chin DC, Hsieh CC, Lin HY, Yeh KW. A low glutathione redox state couples with a decreased ascorbate redox ratio to accelerate flowering in oncidium orchid. Plant Cell Physiol. 2016;57:423-36.

177. Giraud E, Van Aken O, Ho LHM, Whelan J. The transcription factor ABI4 is a regulator of mitochondrial retrograde expression of ALTERNATIVE OXIDASE1a. Plant Physiol. 2009;150:1286-96.
178. Giraud E, Ho LHM, Clifton R, Carroll A, Estavillo G, Tan Y-F, et al. The absence of ALTERNATIVE OXIDASE1a in Arabidopsis results in acute sensitivity to combined light and drought stress. Plant Physiol. 2008;147:595-610.

179. Amirsadeghi S, Robson CA, McDonald AE, Vanlerberghe GC. Changes in plant mitochondrial electron transport alter cellular levels of reactive oxygen species and susceptibility to cell death signaling molecules. Plant Cell Physiol. 2006:47:1509-19.

180. Samson F, Brunaud V, Balzergue S, Dubreucq B, Lepiniec L, Pelletier G, et al. FLAGdb/FST: a database of mapped flanking insertion sites (FSTs) of Arabidopsis thaliana T-DNA transformants. Nucleic Acids Res. 2002;30:94-7.

181. Mortazavi A, Williams BA, McCue K, Schaeffer L, Wold B. Mapping and quantifying mammalian transcriptomes by RNA-Seq. Nat Methods. 2008;5: $621-8$.

182. Benjamini $Y$, Hochberg Y. Controlling the false discovery rate: a practical and powerful approach to multiple testing. J R Stat Soc Ser B. 1995;57:289300.

183. Reimand J, Kull M, Peterson H, Hansen J, Vilo J. g:Profiler-a web-based toolset for functional profiling of gene lists from large-scale experiments. Nucleic Acids Res. 2007;35:W193-200.

\section{Publisher's Note}

Springer Nature remains neutral with regard to jurisdictional claims in published maps and institutional affiliations.
Ready to submit your research? Choose BMC and benefit from:

- fast, convenient online submission

- thorough peer review by experienced researchers in your field

- rapid publication on acceptance

- support for research data, including large and complex data types

- gold Open Access which fosters wider collaboration and increased citations

- maximum visibility for your research: over $100 \mathrm{M}$ website views per year

At BMC, research is always in progress.

Learn more biomedcentral.com/submissions 